\title{
HALLAZGO DE UNA CABEZA CERCENADA (“CABEZA TROFEO”) EN EL VALlE dE NASCA (PERÚ): DETRÁS DEL RITUAL Y LA VÍCTIMA
}

\author{
Juan Carlos De La Torre Z. ${ }^{1}$
}

\begin{abstract}
Resumen
El hallazgo de una cabeza cercenada ("cabeza trofeo") en el yacimiento de El Trigal, valle de Nasca (Perú), nos lleva a desarrollar un análisis reflexivo acerca de las prácticas violentas que se instauraron en la región a inicios del s. I de nuestra era. Inmersas dentro de una lectura del imaginario religioso (rituales) y expresión de políticas de poder, las "cabezas trofeo" se encuentran además en profusas representaciones iconográficas de la materialidad social Nasca. A ello se suman recientes hallazgos de cuerpos desmembrados y con huellas de agresión por armamento, además de otros reportes bioantropológicos que advierten una alta representatividad de lesiones por causas violentas, lo cual nos sugiere una lectura de políticas de violencia física (coercitivas) que ejerció esta sociedad, muchas veces encubiertas por el velo ideológico (religioso), con el fin de legitimar el orden social y político en la región.
\end{abstract}

Palabras claves: cabezas trofeo - ritual - violencia - coerción - poder.

The discovery of a severed head ("trophy head") at the site of El Trigal, Nasca Valley (Peru), leads us to develop a reflective analysis about the violent practices that were established in the region early in the Century I AD. Immersed in the reading of religious imaginary (rituals) and expression of power politics, the "trophy heads" are also in profuse iconographic representations of social materiality Nasca. Also, the existence of dismembered bodies and with marks of aggression, and other bioanthropological reports that warn highly representative of injuries caused by violence, suggests a physical violence policy (coercive) used in this society, often concealed by the ideological veil (religious), for purpose of legitimizing social order and politic in the region.

Key words: trophy heads - ritual - violence - coercion - power. Recibido: febrero 2012. Aceptado: abril 2013.

\section{* Introducción}

Es amplio el repertorio de representaciones iconográficas de cabezas cercenadas, comúnmente denominadas "cabezas trofeo", en toda el área Andina, y principalmente en los Andes Centrales. No es de extrañar que la profusa representación de estos motivos sobre diversos soportes materiales y su correlación con la evidencia empírica (bioantropológica) en contextos arqueológicos, hayan llevado a muchos investigadores e investigadoras a dilucidar la importancia y función de estos singulares objetos en las sociedades precolombinas.

Desde inicios del siglo pasado existe una gran controversia en argumentar el origen de las "cabezas trofeo" producto de los primeros hallazgos obtenidos en la costa sur de Perú (Figura 1) (Uhle 1914; Tello 1918). Esta controversia gira en torno a la procedencia, obtención y uso de estas cabezas cercenadas de sus cuerpos, que suelen vincularse con prácticas rituales (batallas rituales, culto a los ancestros, ritos de renacimiento, de fertilidad agrícola, etc.) (Tello 1918; Coelho 1972; Neira y Coelho 1972-1973; Browne et al. 1993; Carmichael 1994, 1995; DeLeonardis 2000; Proulx 2001; Conlee 2007) y prácticas militares violentas relacionadas con posibles víctimas de guerra y/o prisioneros decapitados (Uhle 1914; Roark 1965; Pezzia 1968; Baraybar 1987; Proulx 1989; Verano 1995). También se ha expuesto una complementariedad de ambas explicaciones, por lo cual dichas cabezas serían obtenidas mediante prácticas militares violentas, con decapitación de las víctimas, para luego ser usadas en prácticas rituales (Baraybar 1987; Proulx 1989; Tung et al. 2007;

\footnotetext{
1 Departamento de Prehistoria. Universidad Autónoma de Barcelona. Avenida Madrid 5 Esc. A 60-1ㅇ. 08028 Barcelona, ESPAÑA. Email: jc.delatorre.zevallos@gmail.com
} 


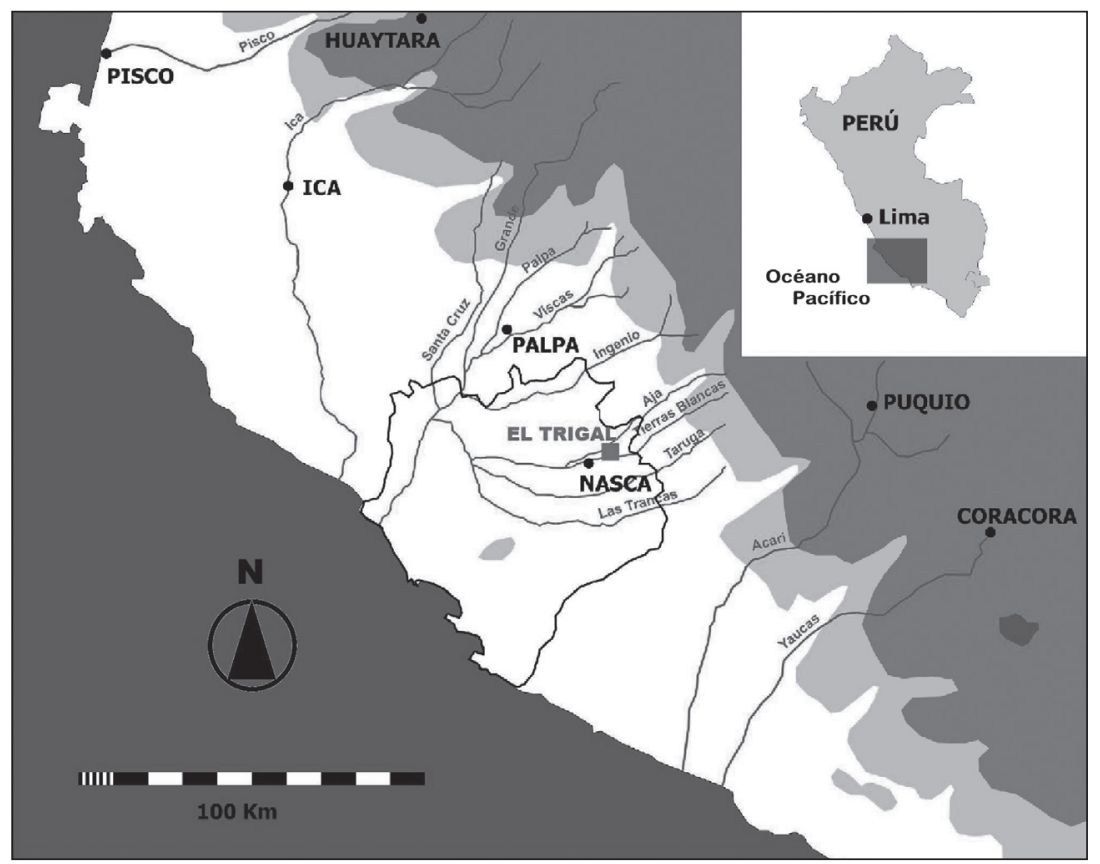

Figura 1. Mapa de la costa sur de Perú y ubicación del sitio El Trigal.

Tung y Knudson 2008, 2010). Orientados a dilucidar mejor estas explicaciones, en la actualidad ha cobrado gran interés la aplicación de estudios bioantropológicos para el análisis de este tipo de restos; así se han realizado rigurosos exámenes osteológicos (Williams et al. 2001; Forgey y Williams 2003) y exámenes físico-químicos que van desde los análisis genéticos de ADN (Forgey y Williams 2005) hasta la aplicación de isótopos de estroncio, carbón y oxígeno para el estudio de paleodietas sobre muestras obtenidas en diversos contextos de los Andes Centrales (Tung 2007; Finucane 2008; Tung y Knudson 2008, 2010; Conlee et al. 2009; Knudson et al. 2009).

En los últimos años se han planteado una serie de interpretaciones que llevan a argumentar, a partir de fuentes arqueológicas, etnográficas y etnohistóricas, un abanico de significados político-ideológicos referentes a la importancia de las cabezas humanas cercenadas de sus cuerpos en los Andes y las prácticas rituales que las envuelven (Arnold y Hastorf 2008). Sin embargo, creemos que es necesario ahondar más en estas interpretaciones. Más allá de definir una explicación directa de sus orígenes rituales o su obtención mediante prácticas militares, se requiere ver detrás del cristal opaco de la argumentación cosmogónica insustancial con que suele percibirse. ¿Qué existe detrás de estas prácticas rituales?, y icuál es la real fundamentación políticoideológica que les dio origen? Es necesario otorgar una significación sociológica y explicar el marco sociohistórico en el cual se realizaron estas prácticas sobre el tratamiento de cuerpos humanos en la prehistoria de los Andes, y particularmente en el tratamiento de las denominadas "cabezas trofeo" Nasca.

Hayan sido prácticas rituales o presentado un cariz de origen bélico, es necesario avanzar en el (re)conocimiento de realidades diferentes a las que se vienen reproduciendo acerca de este tipo de contextos. Así, teniendo como pretexto el hallazgo de una cabeza cercenada, enterrada en urna, en el sitio El Trigal en el valle de Nasca, costa sur de Perú, además de considerar algunos contextos funerarios documentados en el sector necrópolis -los cuales serán tratados con mayor detalle y en extensión en otros reportes que venimos elaborando debido a la complejidad de los hallazgos- desarrollamos en el presente artículo un análisis que nos permita aproximarnos al entendimiento de este tipo de prácticas que legitimarían un orden social imperante dentro de un marco discursivo de prácticas político-ideológicas que ejerció y estableció la sociedad Nasca entre los s. I-VII DC. 


\section{* El ritual y la víctima}

¿Batallas rituales? ¿Culto a los ancestros? ¿Ceremonias de renacimiento? ¿Ritos de fertilidad agrícola? ¿Qué fundamentos políticos-ideológicos naturalizan una práctica violenta que permite la decapitación ${ }^{2}$ o cercenamiento de la cabeza de un individuo o grupo de individuos? Entendemos que los rituales son prácticas simbólicamente diferenciadas de las actividades cotidianas en términos de forma de acción y propósito (Aranda y Esquivel 2006). Estas prácticas, como lenguaje simbólico de comunicación, se mantienen sobre una estructura político-ideológica que sustenta y determina las relaciones sociales de la sociedad que las practica. De este modo, los rituales sirven comúnmente para crear y mantener un sentido de comunidad y pertenencia (p.e., caso de grupos tribales de la amazonía cazadores de cabezas; Harner 1972). Sin embargo, recientemente se ha centrado la atención en el papel que juega el ritual en crear, definir y transformar las estructuras de poder, como un poderoso medio de dominación, pero también de contestación (Aranda y Esquivel 2006).

En la creación y mantenimiento de las diferentes formas de dominación, el desarrollo de la práctica ritual es fundamental ya que es la forma mediante la cual, la ideología dominante es naturalizada limitando la percepción de posibles alternativas o el reconocimiento de su arbitrariedad. Quien controla el ritual posee el medio para imponer su propia visión del orden social protegiéndola de otros modos de pensamiento (Aranda y Esquivel 2006). Así, el ritual se convierte en un instrumento de dominación y lugar para la naturalización simbólica de la realidad, para su mistificación en la práctica social, y un medio de contestación y transformación del poder (Bloch 1989). Por ello, no es ajeno que toda práctica social envuelta de un trasfondo ideológico -ritual- forme parte de las formas de legitimación del orden social imperante, impuesto por el grupo o colectivo que afianza su poder. De este modo, las prácticas rituales cumplen la función de canalizar y

2 Entendemos la "decapitación" como la acción de cortar la cabeza (Diccionario de la Real Academia Española), sean estos individuos vivos o muertos. Ajenos a la discusión sobre si las denominadas "cabezas trofeo" provienen de individuos muertos de larga data o de una muerte reciente previa o producto de la decapitación (Finucane 2008; Valdez 2009), creemos que la intención de cortar o separar la cabeza de su cuerpo tiene como propósito comunicar psicológica y físicamente la intimidación de un acto. regular lo ordinario o extraordinario, en modo tal que el hilo conductor de la vida social no sea alterado en forma substancial por acciones o reacciones externas al grupo o de la sociedad, así como de los propios individuos, potenciales víctimas, inmersos en estas prácticas.

Las prácticas violentas naturalizadas mediante el ritual, se materializan sobre los propios individuos ("víctimas") en un estado de dominación (coerción). Las víctimas no obedecen a un acto participativo y voluntario ante una situación de violencia física. Es la fuerza impositiva, muchas veces camuflada sobre la base de un "orden" de obligada adhesión (religión), que normativiza la conducta social y conduce a la concreción de estos actos (en sacrificios, ofrendas, ceremonias, etc.). Es por ello que, en gran parte, todas las lecturas socio-ideológicas que de ellas -las prácticas violentas- se originan ("batallas rituales", "renacimiento", "fertilidad", etc.), desvirtúan la realidad en un afán de resaltar lo mágico-religioso frente a lo real-histórico.

En el caso Nasca, no solo las evidencias físicas de las propias cabezas cercenadas (individuos/víctimas) representan el abanico de muestras arqueológicas, igualmente las representaciones iconográficas de las comúnmente llamadas "cabezas trofeo" decoran y/o aparecen reiteradamente en indistintas formas de superficies materiales, siendo la más extensa el soporte cerámico (Roark 1965; Proulx 1971, 1989, 2001; Blasco y Ramos 1974, 1980; Carmichael 1994, entre otros). Esta (re)producción de elementos visuales - cabezas cercenadas- junto a motivos ideográficos sobre un soporte material muy presente en las diversas actividades de la vida cotidiana de esta sociedad, magnifica esta práctica, mientras que, como se ha propuesto para otras sociedades prehispánicas (p.e., en el caso de Pukara; Chávez 1992), al mismo tiempo sugiere un control social por amenaza de fuerza o terrorismo visual para prevenir algún evento o conflicto (Chávez 1992). Asimismo, la estandarización de estos motivos iconográficos sugiere un control centralizado y la manipulación del mismo, divulgando un discurso político-ideológico que sustenta las prácticas de decapitación o separación de cabezas de sus cuerpos mediante la ritualidad religiosa. De esa manera se santifica y naturaliza la autoridad dada a un grupo restringido y el monopolio de la fuerza sobre un determinado colectivo (Chávez 1992), con la intención de camuflar una falsa representatividad de la sociedad en su totalidad. 


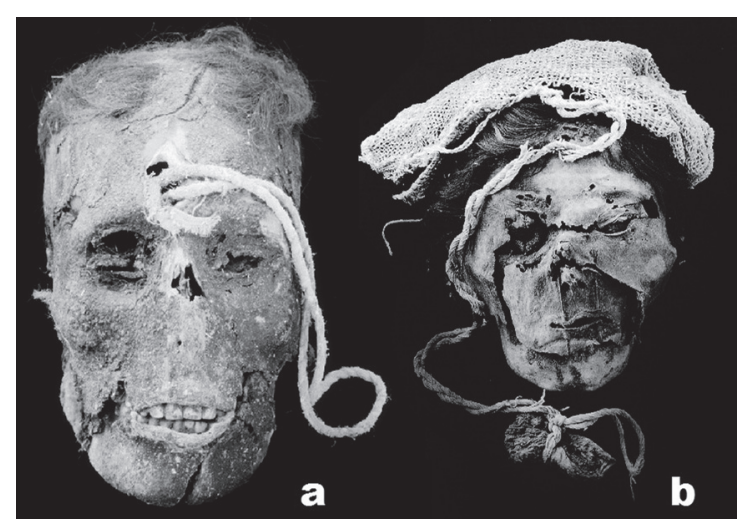

Figura 2. Dos "cabezas trofeo" Nasca. Museo Nacional de Antropología, Arqueología e Historia (Lima, Perú). a) Catálogo: AF: 7051 (Verano 2008: 1055 Fig. 52.9); b) Catálogo: AF: 7508

(Verano 1995: 208 Fig. 9).

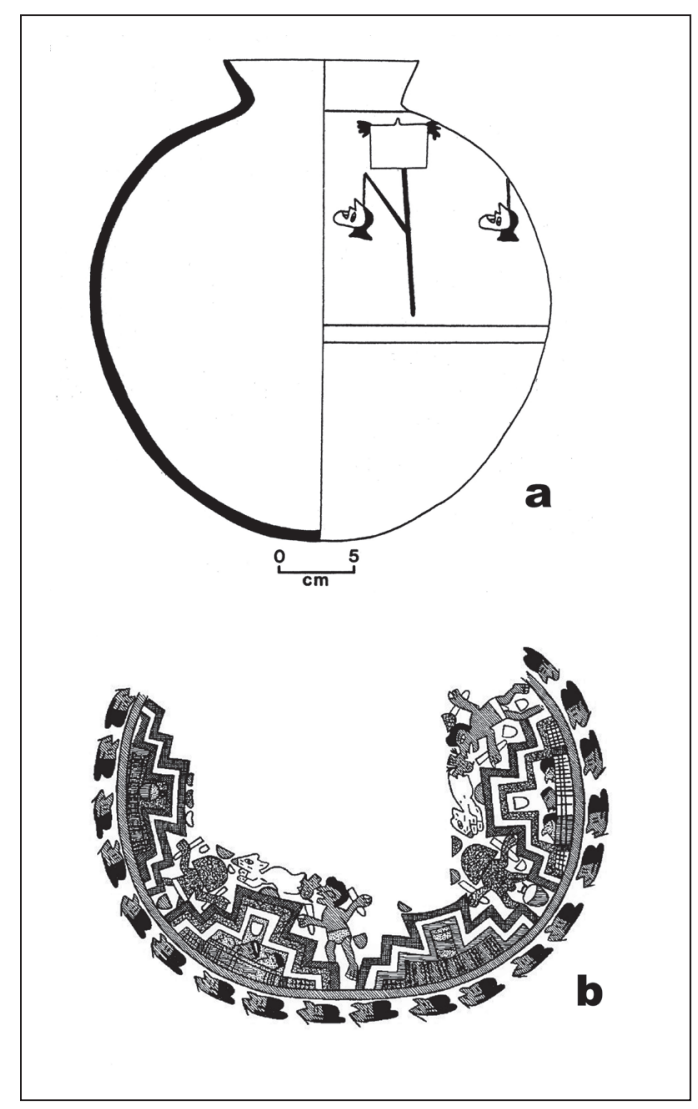

Figura 3. Representaciones figurativas de "cabezas trofeo" en vasijas Nasca. a) Vasija con figuras de "cabezas trofeo" colgando (Blasco y Ramos 1974. Fig. III; Verano 1995: 217 Fig. 13); b) Escena de entierro de cabezas cercenadas en plataformas escalonadas (Silverman y Proulx 2002: 200 Fig. 8.1).

\section{* Las denominadas "Cabezas trofeo" Nasca}

Evidencias arqueológicas de cabezas cortadas han sido registradas en distintas áreas geográficas de los Andes Centrales (Ica, Ayacucho, Moquegua, La Libertad, Lima, etc.) (Uhle 1914; Tello 1918; Pezzia 1968; Coelho 1972; Neira y Coelho 1972-1973; Carmichael 1988, 1995; Browne et al. 1993; Kroeber y Collier 1998; Verano 2001; Kellner 2002, 2006; Bachir y Llanos 2006; Tung 2007; Finucane 2008, entre otros), incluyendo el Noroeste Argentino (Núñez y Tartusi 2002). Por otro lado, en buena parte de la vasta Amazonía fue una práctica que pervivió hasta tiempos no muy remotos entre diversos grupos tribales selváticos (Harner 1972).

Sin embargo, el mayor registro arqueológico de este tipo de prácticas proviene de la costa sur peruana, específicamente de la región geográfica que ocupó la cultura Nasca entre los s. I-VII de nuestra era, y principalmente en la gran mayoría de yacimientos de los departamentos de Ica (Tello 1918; Kroeber 1956; Strong 1957; Baraybar 1987; Carmichael 1988; Browne et al. 1993; Silverman 1993; Kroeber y Collier 1998; Orefici y Drusini 2003; Tomasto 2009, entre otros) y Arequipa; en este último los reportados en el valle de Acarí (Coelho 1972; Neira y Coelho 1972-1973; Kowta 1987), excavados sistemáticamente desde inicios del s. XX hasta ahora. Se han documentado, en el registro arqueológico, más de 150 "cabezas trofeo" Nasca (Tung 2007; Knudson et al. 2009) y algunas evidencias de cuerpos decapitados (DeLeonardis 2000; Conlee 2007); estos últimos, que indirectamente señalan la existencia de cabezas cercenadas de sus cuerpos, en número considerablemente menor con respecto a las cabezas. Recientemente, en el yacimiento de Amato (en Acarí), Valdez (2009; Valdez et al. 2010) ha registrado una serie de contextos funerarios de cuerpos de individuos decapitados de todas las edades y de ambos sexos (Valdez 2009), además del hallazgo de dos cabezas humanas que tuvieron el tratamiento de las denominadas "cabezastrofeo" (Valdez et al. 2010). No obstante, el autor hace un deslinde en torno a la filiación cultural de estos contextos con los de Nasca, asignándoles una filiación local coetánea denominada tradición Huarato (Valdez 2006). ${ }^{3}$

\footnotetext{
3 Es interesante anotar que en esta zona de Acarí también existen reportes de "cabezas-trofeo" (Coelho 1972; Neira y Coelho 19721973; Kowta 1987) que forman parte del registro Nasca.
} 


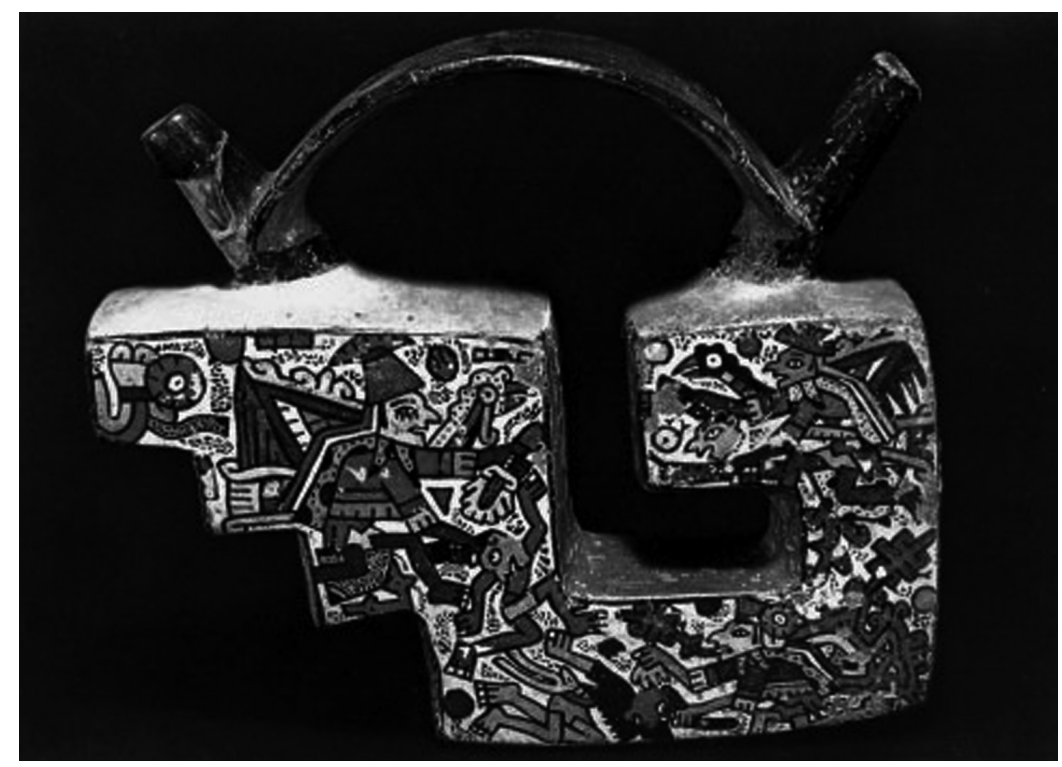

Figura 4. Vasija Nasca con escena de guerra y decapitación. Museo Amano (Lima, Perú) (Silverman y Proulx 2002: 232 Fig. 9.2).

Los reportes señalan que estas cabezas fueron enterradas de forma aislada, tanto en espacios residenciales (Coelho 1972; Neira y Coelho 1972-1973; Orefici y Drusini 2003; Bachir y Llanos 2006) como en espacios funerarios (Kroeber y Collier 1998), de manera grupal junto a otras cabezas (Baraybar 1987; Browne et al. 1993) o asociadas a sepulturas como ajuar u ofrenda (Silverman 1993; Kroeber y Collier 1998; Orefici y Drusini 2003). Ampliamente conocidas bajo la denominación de "cabezas trofeo", debido a la interpretación que les otorgaron algunos investigadores (Uhle 1914; Tello 1918) como trofeo de prácticas militares en la antigüedad, se definen por la presencia de dos características principales: 1) la perforación de un orificio en el hueso frontal, hecho con la finalidad de pasar a través de él una cuerda a modo de asidero, la cual se sujetaba al interior del cráneo por un simple nudo o atado a trozo de madera; 2) la rotura del occipital mediante una ligera ampliación del foramen magnum hasta obtener una completa remoción de la base del cráneo con la finalidad de extraer la masa encefálica (Browne et al. 1993; Verano 1995, 2001, 2003; Proulx 2001). Asimismo, dentro del repertorio de "cabezas trofeo" Nasca, a pesar de recurrentes características generales, se plantea una variabilidad que singulariza cada elemento, como en el caso de la posición y tamaño de la perforación del orificio del hueso frontal (Williams et al. 2001) que varían según el tipo de cuerda a la que posible- mente se sujetaba, sea ésta de fibra vegetal, de algodón o cabello humano (Verano 1995, 2003). También la cavidad basal (orificio del foramen magnum) varía en tamaño según la complejidad de la elaboración de la cabeza trabajada. Dicha variabilidad además se encuentra en las representaciones iconográficas que cambian de acuerdo al trazo figurativo que plasmó el/la artesano/a nasquense (Carmichael 1994; Proulx 2006). En muchos casos las cabezas fueron halladas con los labios cosidos con espinas de algarrobo o cactus, y la mandíbula inferior atada a los arcos zigomáticos para mantenerla en su ubicación original (Browne et al. 1993) (Figura 2). Con ello se intentaba conservar el estado original del rostro (Verano 1995), usando, además, en algunos casos, algodón y tela para rellenar las mejillas y los orificios de los ojos del individuo.

En cuanto a las representaciones iconográficas Nasca de "cabezas trofeo", la cerámica es una de las principales fuentes gráficas para el estudio e interpretación de estos singulares "objetos". Muchos de los elementos iconográficos representados muestran una profusa cantidad de figuras naturales y estilizadas de cabezas cercenadas que adornan las paredes de vasijas (Figuras 3), además de textiles y otros soportes materiales. Igualmente, se representan escenas realistas que dibujan el acto de la decapitación (Figura 4) (DeLeonardis 2000:377-378, Figs. 


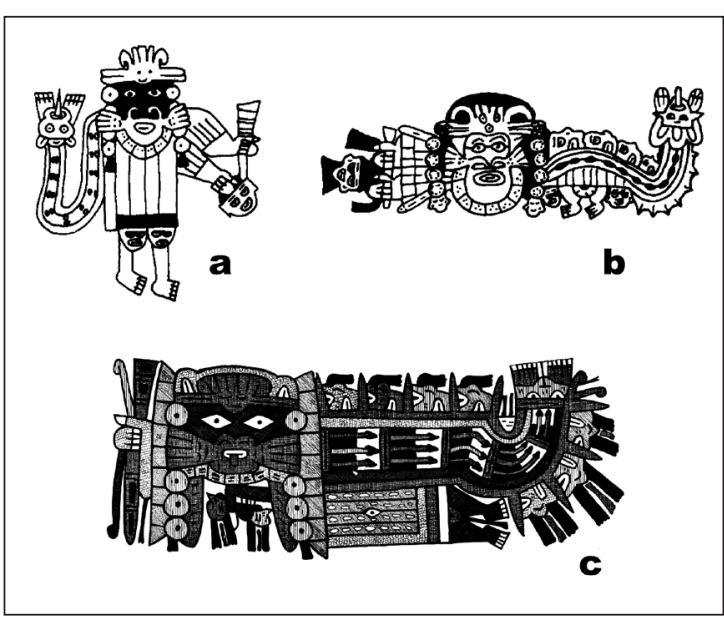

Figura 5. Representación de personajes sobrenaturales Nasca ("seres míticos antropomorfos") portadores de "cabezas trofeo". a) y b) Nasca Temprano (Forkass 1981: 57 Fig. a) 171, b) 175); c) Nasca Medio (Roark 1965: Plate VIII Fig. 40).

14-15), además de personajes portadores de cabezas e individuos decapitados, en su mayoría, asociados a figuras de la cosmogonía Nasca.

Las representaciones de "cabezas trofeo" en la cerámica Nasca visualizan un sinnúmero de elementos individuales o se presentan en forma conjunta con una serie de personajes míticos, que en algunos casos arrastran similitud con personajes de la iconografía Paracas Tardío (Frame 2001; Proulx 2001). Es el caso de los "seres míticos antropomorfos" (personajes sobrenaturales) (Figura 5) asociados a las fases tempranas de Nasca (Figura 5a-b), finamente ataviados y portando "cabezas trofeo" en sus manos, similares al personaje del "Ser Oculado" en Paracas, además de las "criaturas míticas", tales como "la ballena asesina", "el ave horrible", "las aves arpías", "el gato moteado", entre otros (Blasco y Ramos 1980; Forkass 1981; Proulx 1989, 2001; Carmichael 1994), que repiten similar patrón gráfico o en cuyos componentes se agregan cabezas humanas, sean éstas más naturales o estilizadas. Además, la presencia de elementos agrícolas en algunas de estas representaciones de personajes míticos con "cabezas trofeo" (Roark 1965; Blasco y Ramos 1974; Proulx 2001, 2006, entre otros), ha llevado a diversos investigadores a inferir situaciones de ritualidad dirigidas a los cultos de "fertilidad", "regeneración" y "renacimiento" agrícola, entre otros (DeLeonardis
2000; Proulx 2001; Silverman y Proulx 2002; Conlee 2007); así como las sugerentes representaciones de enterramiento de cabezas cercenadas (Figura $3 \mathrm{~b}$ ) han sido relacionadas por otros a posibles ritos de "culto a los ancestros" (Carmichael 1988; Silverman 1993). A partir de estas lecturas se ha pretendido interpretar diversos contextos arqueológicos con evidencias de "cabezas trofeo" (Carmichael 1988; Browne et al. 1993; Silverman 1993), y en otros casos, de cuerpos decapitados (DeLeonardis 2000; Conlee 2007).

Finalmente, el escenario gráfico cambia durante el período Nasca Tardío (s. V-VII DC), y de los "personajes míticos antropomorfizados" se pasa a representaciones más realistas donde las escenas militares adquieren mayor importancia (Roark 1965). Los elementos agrícolas se solapan con elementos bélicos (armas) (Figura 5c) y los "personajes míticos" son reemplazados por "guerreros". Sin embargo, se observa una continuación de elementos figurativos de "cabezas trofeo", aislados, como componentes complementarios en la decoración de vasijas.

\section{* Excavaciones en la cuenca del río Nasca (ICA-Perú): El Trigal}

Desde el año 2005 se desarrolla un estudio sistemático de las comunidades prehispánicas del valle de Nasca, en torno a poblaciones que registran una cronología que va desde el primer milenio AC hasta el s. IV DC, dentro del marco de investigaciones que desarrolla el Proyecto Arqueológico La Puntilla. ${ }^{4}$ Dichos trabajos se vienen realizando en el área arqueológica de La Puntilla (Nasca), territorio localizado entre los valles bajos de los ríos Aja y Tierra Blanca, afluentes que conforman el valle de Nasca, separados por la cadena montañosa del cual deriva el nombre del área. Sin embargo, la documentación arqueológica que revisa el presente artículo procede del yacimiento arqueológico El Trigal (LP2) (Figura 6), identificado inicialmente el año 2001 durante trabajos de reconocimiento (De La Torre 2005; De La Torre y

\footnotetext{
4 Gracias al financiamiento otorgado por el Ministerio de Cultura de España (Programa de Proyectos Arqueológicos en el Exterior 2005-2010) y de la Agència de Gestió d'Ajuts Universitaris i de Recerca de la Generalitat de Catalunya (Programa Excava 20062009) y los permisos concedidos por el anterior Instituto Nacional de Cultura de Perú, actual Ministerio de Cultura de Perú.
} 


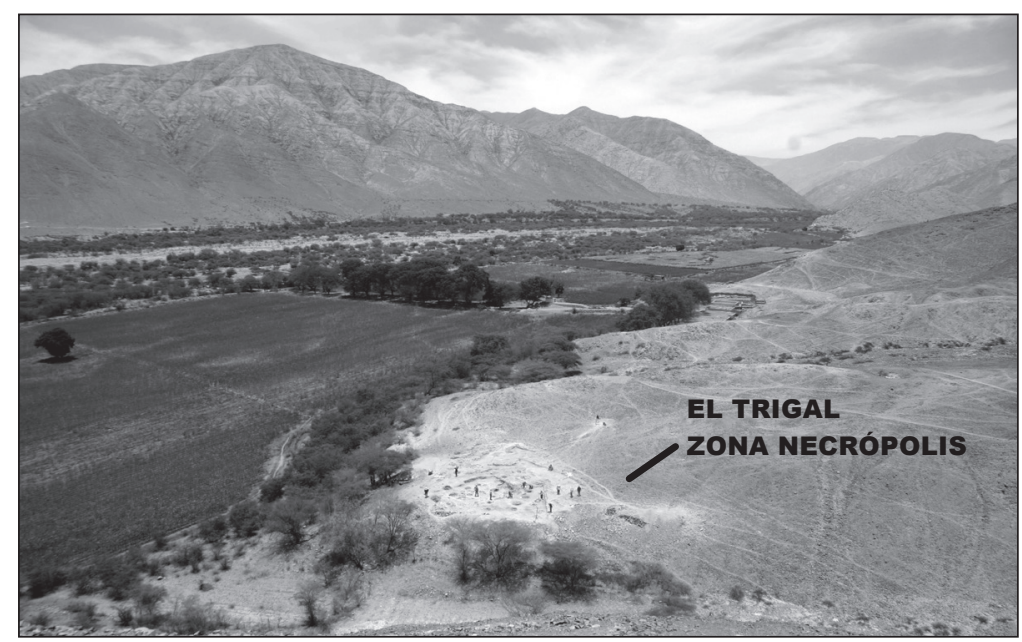

Figura 6. Necrópolis del yacimiento El Trigal (Nasca, Perú).

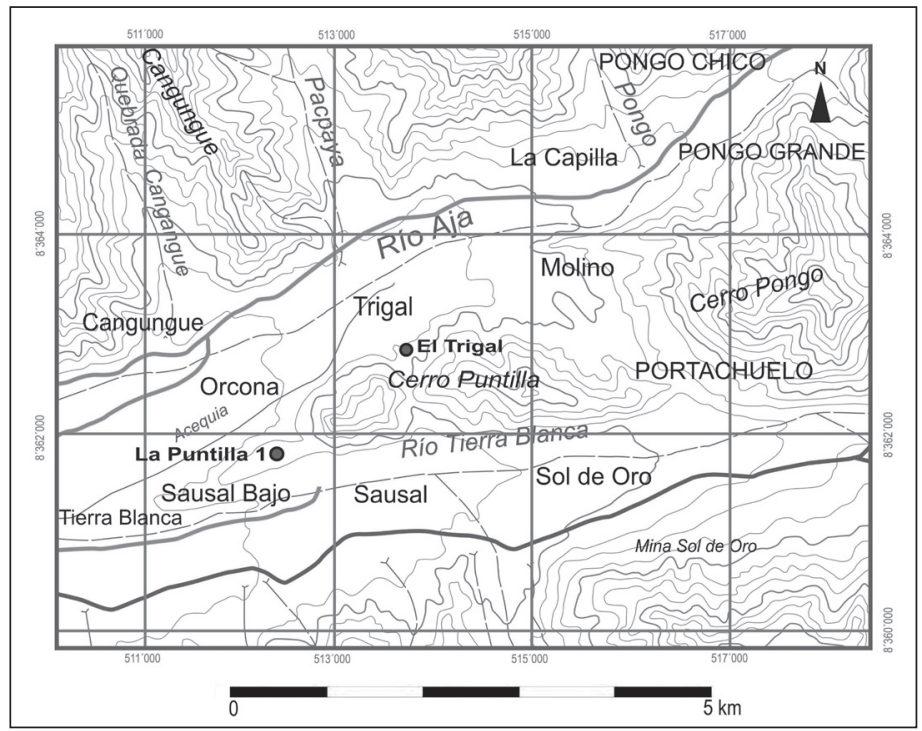

Figura 7. Ubicación de El Trigal y área de estudio del Proyecto La Puntilla (Cerro Puntilla) entre los ríos Aja y Tierra Blanca. Dibujo de J. Ponce. Fuente: Instituto Geográfico Nacional de Perú.

Van Gijseghem 2005) y donde se han venido realizando excavaciones sistemáticas extensivas, a partir del año 2005, durante cinco campañas consecutivas (De La To-

5 Los trabajos de reconocimiento inicial se llevaron a cabo por el autor conjuntamente con Hendrik Van Gijseghem de la Universidad de California-Santa Barbara, en el marco de los trabajos de prospección y excavación en el yacimiento arqueológico de La Puntilla, durante el año 2001. rre y Castro-Martínez 2006, 2007; Castro-Martínez et al. 2008, 2009, 2011).

El Trigal se localiza entre las coordenadas UTM 513600 E y $8362850 \mathrm{~N}$ (Figura 7), en el margen izquierdo del río Aja, un afluente de la cuenca del río Grande, aproximadamente a $7 \mathrm{~km}$ al este del actual pueblo de Nasca, perteneciente a la provincia del mismo nombre. Este yacimiento, 


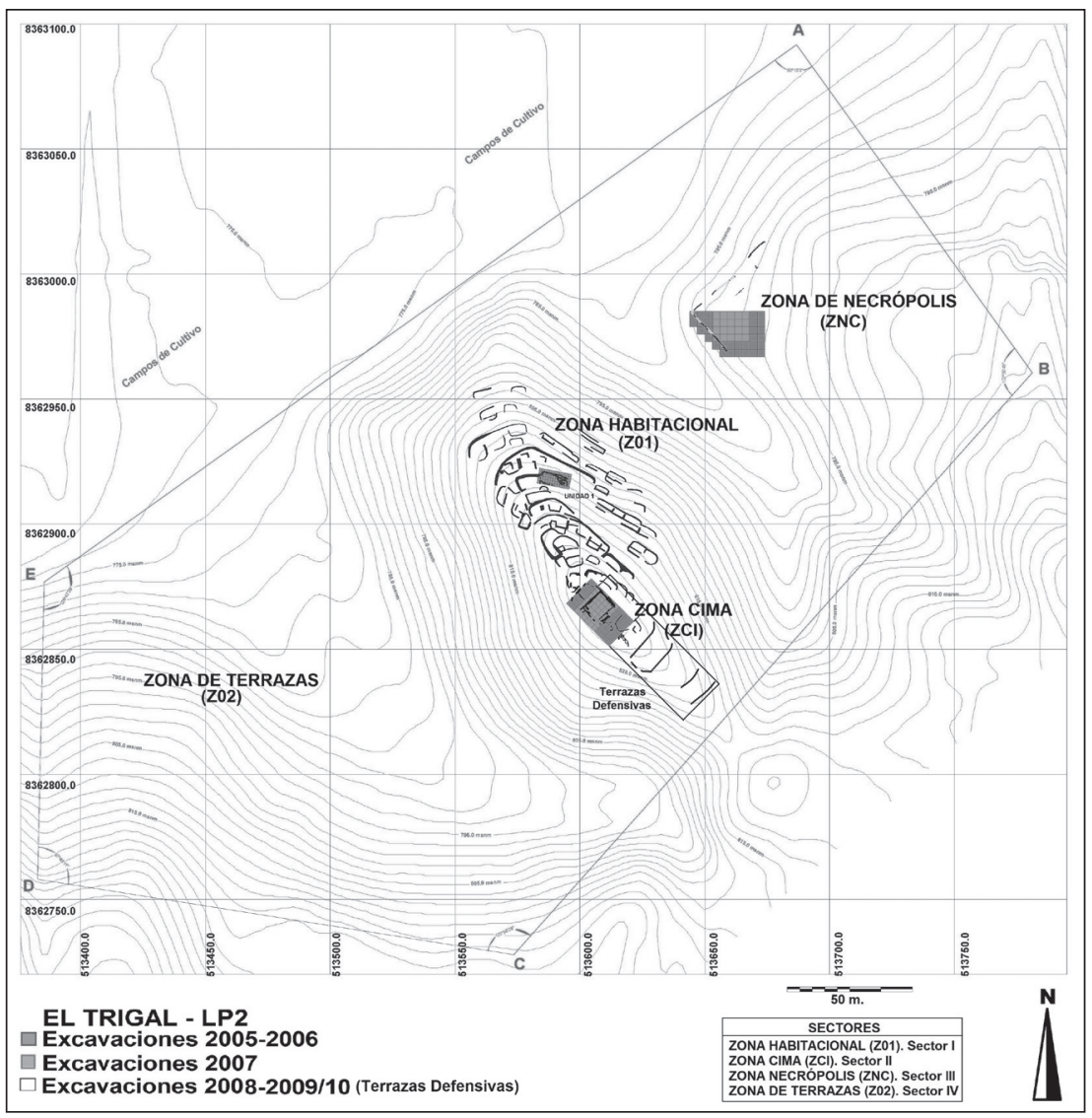

Figura 8. Sectores y áreas de excavación del yacimiento El Trigal.

como la mayor parte de los asentamientos prehispánicos de la zona, se encuentra en la sección intermedia de la cadena de cerros rocosos que conforman el área de La Puntilla y donde empieza la pendiente ascendente de las primeras estribaciones de la vertiente occidental de los Andes. La altitud del terreno varía en esta zona entre 740 y $820 \mathrm{~m} . \mathrm{snm}$. El medio geográfico en el que se encuentra está definido como una formación ecológica de Desierto Pre-montano, con un clima pre-árido y semi-cálido. Las precipitaciones son sumamente escasas y no llegan a los $3 \mathrm{~mm}$ de promedio anual.

El asentamiento ocupa la cima y laderas de un pequeño promontorio rocoso que sobresale del resto de la cadena montañosa que encajona el límite sur del valle. Comprende cuatro sectores que se definen por su ubicación y composición estructural (Figura 8): los dos primeros corresponden a áreas estructurales más antiguas que presentan eviden- cias de una fase ocupacional temprana entre ca. 700-600 y 100-150 cal. AC de época Paracas, y los dos últimos de filiación Nasca entre ca. 50-100 y 350-400 cal. DC.

El primer sector (sector I) corresponde a zonas de habitación (Zol) o estructuras aterrazadas de plantas alargadas o semi-ovaladas. Las excavaciones permitieron definir una estructura habitacional de planta alargada con muros de contención y acondicionamiento de la ladera rocosa. Se registraron áreas de actividad doméstica cuyo contexto principal lo conformaba un fogón asociado a artefactos de molienda, así como áreas de desechos orgánicos y restos de de cerámica (De La Torre y Castro-Martínez 2006). El segundo sector (sector II), en proceso de excavación, corresponde a la zona de cima (ZCI). Los trabajos de excavación en este sector fueron los más intensos. Las estructuras arquitectónicas registradas se encuentran vinculadas al almacenamiento y procesado de productos alimenticios (fri- 


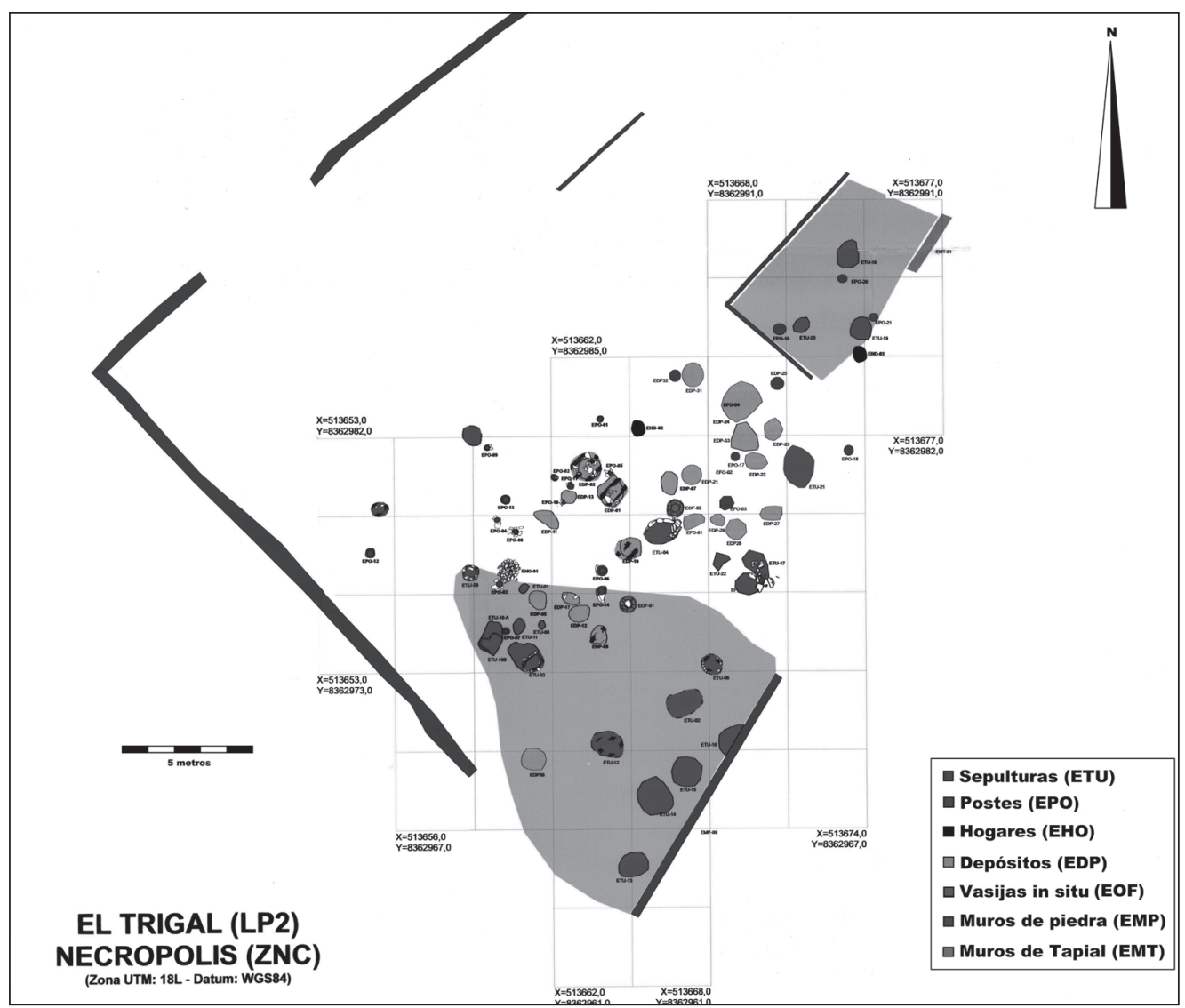

Figura 9. Zona de necrópolis o sector III de El Trigal. Localización de contextos funerarios (ETU) y elementos arquitectónicos.

jol, maíz), y artefactos varios, en un primer momento de ocupación (Edificio de los Almacenes) y a patios-talleres o espacios de trabajos artesanales (Spondylus, obsidiana, moluscos varios, hueso, etc.) en un segundo momento (Edificio de los Patios). En el área periférica sur de la cima se localizaron una serie de terrazas defensivas (sistema defensivo) conjuntamente con una serie de cúmulos de proyectiles de honda (guijarros) que evidencian la restricción del acceso y salida en ambos momentos de ocupación de la cima, tanto del edificio principal de los "patios" como de los "almacenes", y al conjunto general del asentamiento. Los fechados llevados a cabo en ambos sectores (Iy II) señalan una fase ocupacional inicial pre-Nasca que va desde ca. 700-600 AC a ca. 150-100 AC (Castro-Martínez et al. 2008, 2009, 2011).

El sector III o zona de necrópolis (cementerio) (ZNC) (Figura 9), de donde proceden los restos bioantropo- lógicos aquí analizados, se localiza en la parte baja del cerro al noreste de los sectores I y II, sobre una plataforma aluvial y una leve ladera ascendente a la cadena montañosa del cerro Puntilla. Este sector se encuentra delimitado por gruesos muros perimétricos hechos de piedras angulares y cantos rodados de gran tamaño. Los espacios estructurados del mismo se acondicionan en plataformas arquitectónicas que delimitan áreas de tumbas de filiación Nasca Temprano. También se localizaron estructuras asociadas a otros usos, contemporáneas y anteriores al cementerio. En este sector hallamos una cabeza cercenada en el interior de una urna conjuntamente con un buen número de tumbas de individuos de diferentes edades y de ambos sexos. $\mathrm{Y}$, finalmente, al oeste, se encuentra una zona de terrazas ( $\mathrm{OO}$ ) (sector IV) en la sección baja, externa al yacimiento, de similares características a la zona habitacional del sector I (Zo1). 


\section{* Necrópolis y hallazgo de una cabeza CERCENAda Nasca}

La zona de necrópolis (ZNC), lugar del hallazgo de la cabeza cercenada, se ubica al noreste del asentamiento formativo de El Trigal, aproximadamente a $80 \mathrm{~m}$ de distancia y corresponde, de acuerdo a las evidencias halladas, al denominado período Nasca Temprano (ca. 50-100 a 350$400 \mathrm{cal}$. DC). A pesar del lamentable estado de conservación general del sitio, debido al saqueo indiscriminado, las excavaciones realizadas entre los años 2006 y 2007 (De La Torre y Castro-Martínez 2007; Castro-Martínez et al. 2008, 2009) permitieron localizar y documentar un número considerable de contextos funerarios intactos, sin alteración de su depositación original, constituyendo una muestra importante de estos hallazgos en la zona. Sin embargo, fue en la campaña de 2008 cuando se concluyeron los registros y descripciones analíticas de los conjuntos bioarqueológicos excavados hasta el momento y objetos del presente estudio, disponiendo de esta manera de la caracterización de todos los restos humanos documentados (Godoy 2007, 2008; Urízar y Castellanos 2009). Esto ha permitido completar la identificación preliminar (número de individuos, sexo, edad) realizada anteriormente, y obtener una visión en conjunto de la población que se enterró en esta necrópolis. De los 48 individuos registrados (NMI), 17 fueron hallados en contextos funerarios no alterados, lo que permite estimar que el 65\% de las sepulturas habían sido destruidas por saqueos (Castro-Martínez et al. 2009).

Los trabajos en este sector permitieron documentar áreas bien definidas, delimitadas con muros de piedras angulares y cantos rodados, de plantas irregulares, ligeramente cuadrangulares. Hay áreas construidas exclusivamente para contener las sepulturas, posibles áreas reutilizadas de ocupaciones anteriores, así como áreas contemporáneas a las sepulturas donde se realizaron otros tipos de actividades, incluidas las ligadas a las prácticas funerarias. Los modelos de tumbas encontrados comprenden distintas variantes que guardan cierta correspondencia con tumbas Nasca halladas en la cuenca del río Nasca (Orefici y Drusini 2003): fosas simples, pequeñas cámaras laterales con acceso de pozo (tipo "bota") y urnas cerámicas. Los entierros intactos registrados corresponden al grupo de infantes (neonatos) y de algunos individuos adultos, entre los cuales se incluyen los restos de cuerpos desmembrados y la urna con la cabeza cercenada en cuestión. Muchos de estos contextos, aunque no necesariamente todos, presentaron un sello de piedras acumuladas en la superficie de la boca como señal o marcador de tumba.

El registro por sexo y edad de los individuos señala que no parece existir una diferencia significativa en la presencia entre hombres y mujeres. En cuanto a la edad, se documentaron diversos enterramientos infantiles menores de 1 año (neonatos), gracias a su buena preservación in situ. ${ }^{6}$ También parece que ningún individuo sobrepasó los 40-45 años, edad que supondría el límite de la esperanza de vida en los horizontes cronológicos de la necrópolis. No obstante, si no es consecuencia de una conservación diferencial, la población representada ofrece un porcentaje de supervivencia por encima de los 30-35 años, alcanzando el $70 \%$ de individuos de edad determinable. La mortalidad infantil, por debajo del año de vida, representa el $30 \%$ de los casos documentados.

Por otra parte, aunque se documentaron algunos ajuares funerarios en algunas tumbas, se puede señalar que la comunidad de El Trigal no contaba con una riqueza destacable, que, por el contrario, sí se muestra en tumbas de carácter elitista, registradas en otros yacimientos contemporáneos (Silverman 1993; Kroeber y Collier 1998; Orefici y Drusini 2003). La existencia de derechos hereditarios, aún por clarificar, se expresa en el hecho de que los ajuares que acompañan a las sepulturas de El Trigal se asocian de manera destacable a tumbas infantiles (Godoy 2007, 2008; De La Torre y Castro-Martínez 2007; Castro Martínez et al. 2008, 2011).

Los registros permitieron, además, documentar indicios de tratamientos del cuerpo de forma específica,

\footnotetext{
${ }^{6}$ Lamentablemente, los restos óseos de este grupo, durante el último embalaje y traslado (en el año 2008), no soportaron adecuadamente su manejo. Sin embargo, se logró analizar igualmente la totalidad de la muestra recuperada, tanto in situ como en laboratorio. Teniendo en cuenta esta situación, hemos considerado oportuno tomar como principal referente para el presente artículo los primeros análisis llevados a cabo sobre este grupo (Godoy 2007, 2008), por estar realizados a partir de la muestra todavía en un buen estado de preservación. A partir de los mismos han podido corregirse también algunas imprecisiones en los datos de los reportes posteriores, ocasionadas por las alteraciones sufridas en la muestra analizada.
} 

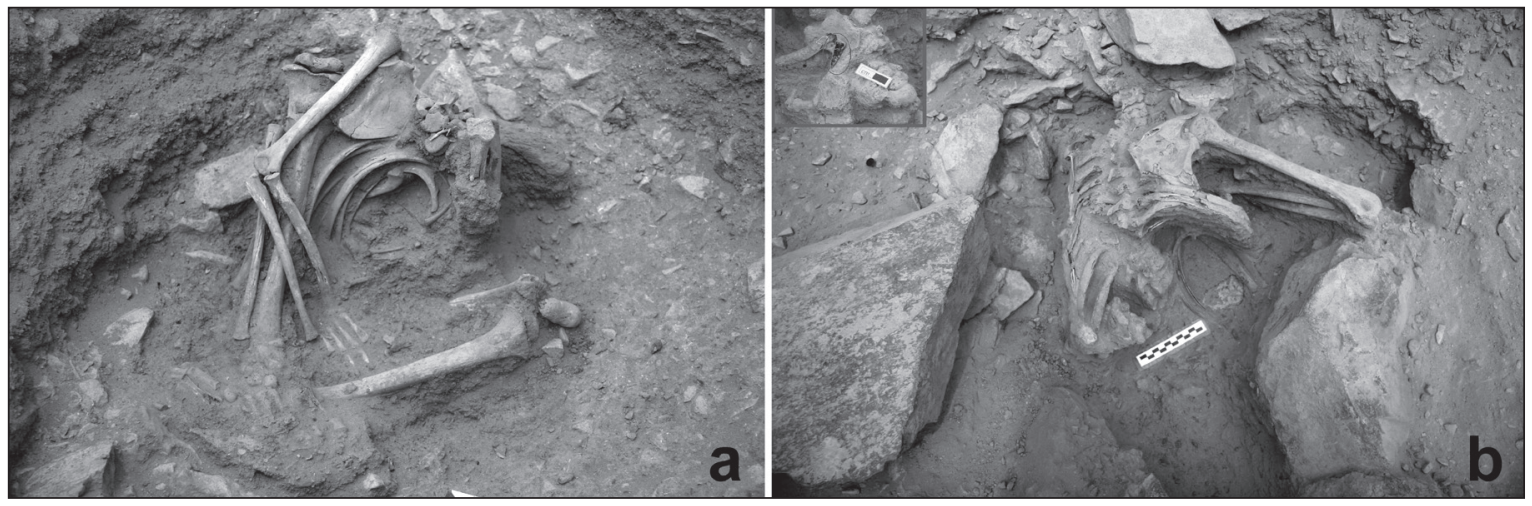

Figura 10. Entierros desmembrados expuestos en la zona de necrópolis (ZNC), El Trigal. a) Infante sin cabeza en posición flexionada (ETU 20); b) Individuo desmembrado con una punta de flecha incrustada a la altura del esternón (ETU 21).

tales como la existencia de deformaciones craneanas, de cuerpos desmembrados, heridos por flechas (Figura 10) y de cabezas separadas del tronco, como es el caso de la cabeza cercenada en cuestión. Entre estos hallazgos destacan los cuerpos sin cabeza de un infante enterrado en fosa en posición flexionada (ETU 20) (Figura 10a) y de un individuo varón adulto desmembrado, igualmente enterrado en fosa, con la sola presencia del tronco y las extremidades superiores bien articuladas, y con una punta de flecha incrustada a la altura del esternón (ETU 21) (Figura 10b). Asimismo, se documentaron los restos de otro individuo adulto que solamente presentaba partes de sus extremidades inferiores, muy bien articuladas (ETU 1OB). De acuerdo a un examen osteológico preliminar (Godoy 2007, 2008; Urízar y Castellanos 2009) no se han encontrado signos de cortes en los huesos analizados. Esto, debido a la ausencia de la mayoría de los restos óseos que formarían parte de las articulaciones directas con las partes desprendidas, lo que nos impide determinar la naturaleza del desmembramiento (Godoy 2007). Sin embargo, la constitución idónea de tales hallazgos in situ (tumbas intactas) y la perfecta articulación de los huesos de los individuos mencionados, sugiere que la separación o cercenamiento de las cabezas de los respectivos cuerpos y la desarticulación o desmembramiento de sus extremidades se realizaron no solo previo al enterramiento, sino también mientras los cuerpos aún conservaban tejido blando, sin precisar si inmediatamente o después de muertos (Godoy 2007. 2008). En gran parte, estas evidencias se pueden vincular a prácticas violentas, más que a un mero tratamiento

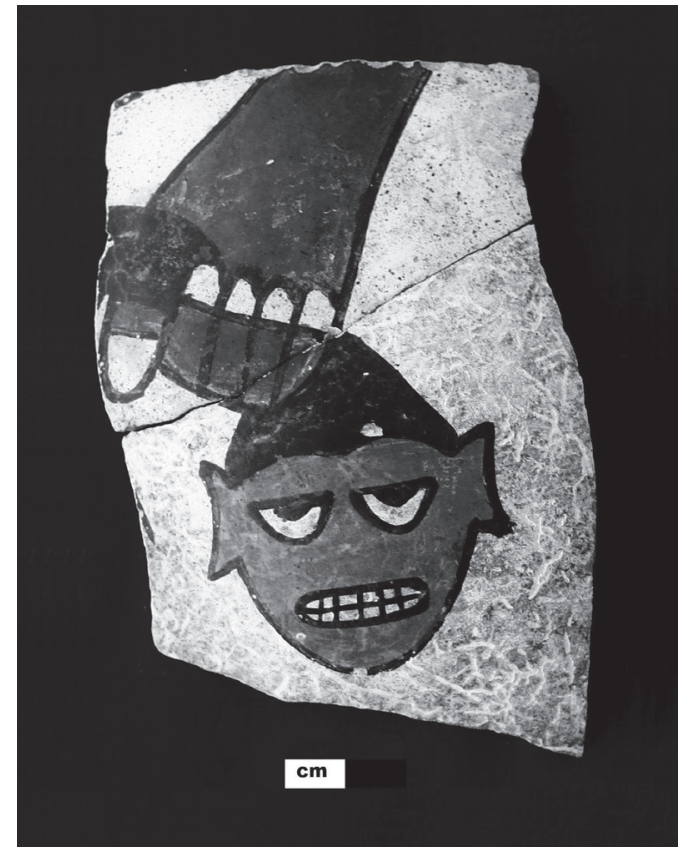

Figura 11. Fragmento de cerámica con representación de una "cabeza trofeo" hallado en la necrópolis (ZNC), El Trigal.

funerario de los cuerpos, considerando además otros reportes de cuerpos decapitados (DeLeonardis 2000; Conlee 2007), de lesiones por agresión (Kellner 2002; Tomasto 2009) y la reiterada iconografía de cabezas cortadas (Figura 11), documentados en la cuenca de Nasca, que corroboran el grado de violencia existente en esta sociedad para la época. 


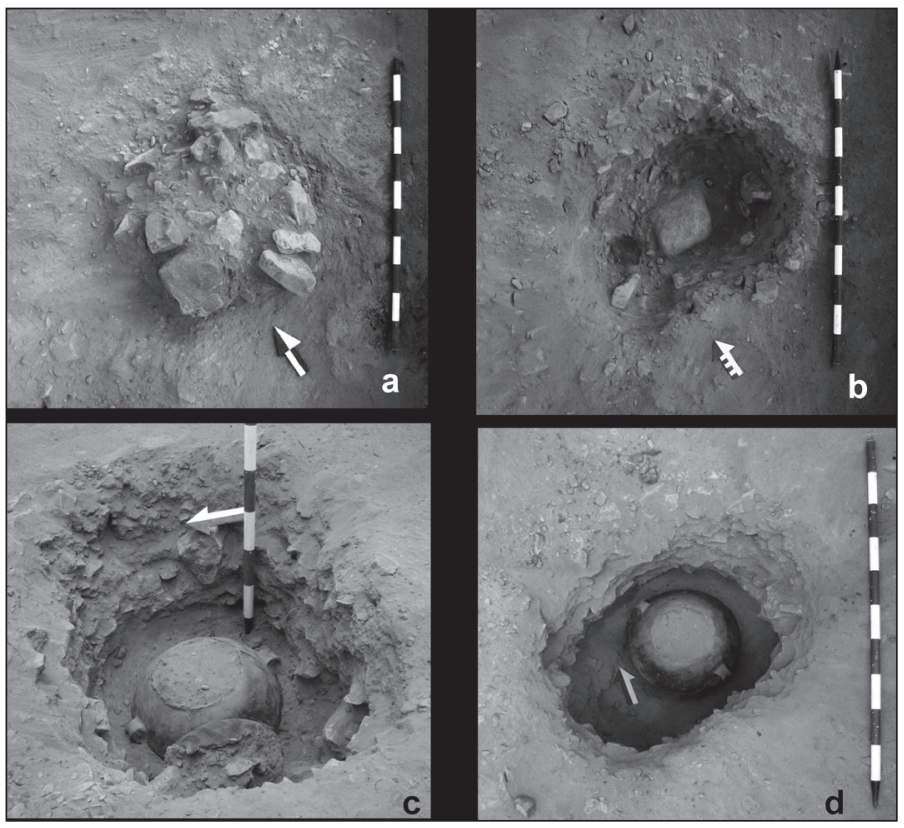

Figura 12. ETU 15. Estructura de la tumba que contenía la urna donde se halló la cabeza cercenada en El Trigal. a) Sello o señal de piedras que localizaba la tumba; b) Presencia de tapa de piedra de la urna; c) Vista frontal de la urna con altura aproximada del pozo de la tumba; d) Vista de planta de la urna de cerámica que contenía la cabeza.

La cabeza cercenada hallada en El Trigal presenta la denominación, en nuestro registro arqueológico, de tumba ETU 15 (estructura de tumba 15) (Figura 12). Ésta se localizó al noreste de una tumba saqueada, junto al muro de piedras (EMP o9) que delimita el lado este de la plataforma principal de la necrópolis (ver Figura 9). Se trata de una estructura en fosa donde se depositó la urna funeraria que contenía el cráneo de un individuo (Figura 13). La superficie de la fosa presentaba un acomodo de piedras angulares y cantos rodados con restos de argamasa de barro con gravilla sellando así la estructura. Dicho acomodo se elevaba a manera de túmulo sobre la boca de la matriz como señal de tumba. La fosa de la tumba, de forma ovalada, de $0.73 \times 0.57 \mathrm{~m}$ de diámetro y $0.68 \mathrm{~m}$ de profundidad, estaba rellena de arena gruesa, tierra suelta, piedras angulares y cantos rodados. La urna es una vasija de cerámica que presenta el cuello roto intencionalmente y una tapa de piedra tipo laja (Figura 13a). Se trata de una olla de cuerpo globular y asas laterales, con restos de hollín en la pared externa. Al lado de la urna se encontró un gran fragmento de cerámica que cubría los restos óseos de un roedor (Cavia porcellus) a manera de ajuar (Figura 13b). Este contexto de inhumación en urna es similar a aquellos hallados en Chaviña (Coelho 1972; Neira y Coelho 19721973) y Tambo Viejo (Kowta 1987) en Acarí.

Una vez extraída la urna funeraria de la necrópolis (Figura 14a) y retirado el sedimento interno de la vasija, el cráneo se encontró incompleto y fragmentado (Figura 14b). A nivel del hueso frontal, presenta un orificio de pequeñas dimensiones y borde irregular (Figura 14c), atravesado por una fractura que, a su vez, delimita con otra fractura transversal a la misma; esta última corre paralelamente a la sutura coronal. El hueso frontal no está completo faltando mayormente su parte izquierda. De igual modo, los huesos temporales y el occipital presentan fragmentación y ausencia de algunas porciones óseas, siendo la parte basal la más ausente. Es probable que la ausencia de estas partes óseas del cráneo se deba al desgaste de las mismas por el uso prolongado de estos singulares "objetos". Tanto la presencia del orificio frontal como la ausencia parcial de la parte basal del cráneo, suelen ser considerados elementos diagnósticos para el reconocimiento de las "cabezas trofeo", por ser característicos de su tratamiento (Verano 2001, 2003). De ese modo se confirmaría el hallazgo de uno de estos "objetos" en la necrópolis de El Trigal. 


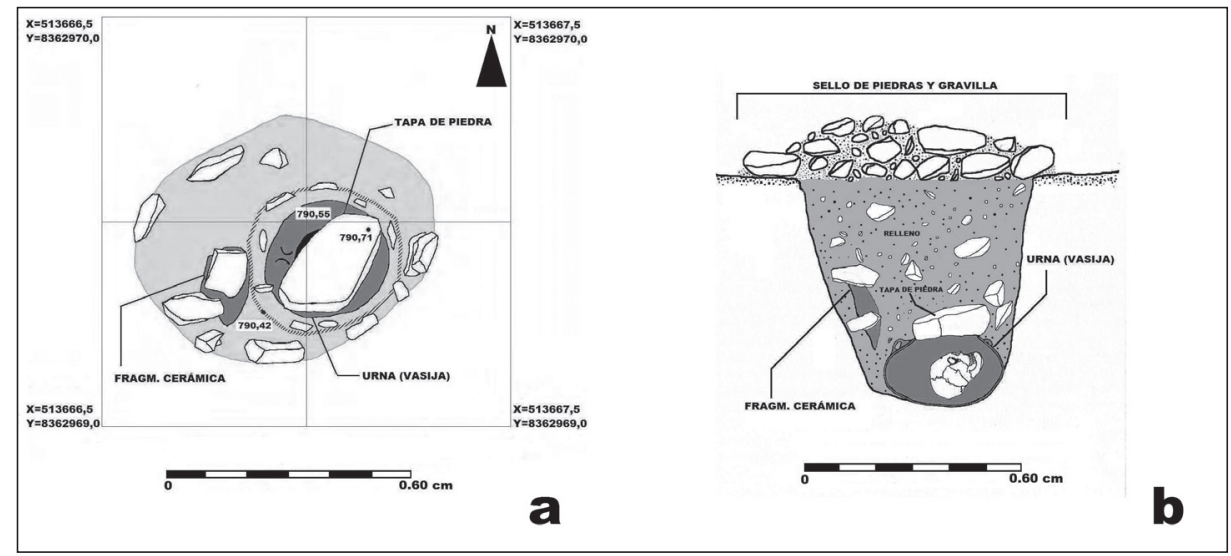

Figura 13. Estructura de la tumba ETU-15, El Trigal. a) Vista de planta ETU 15. Dibujo de M. C. Godoy; b) Vista corte Este-Oeste. Dibujo del autor.

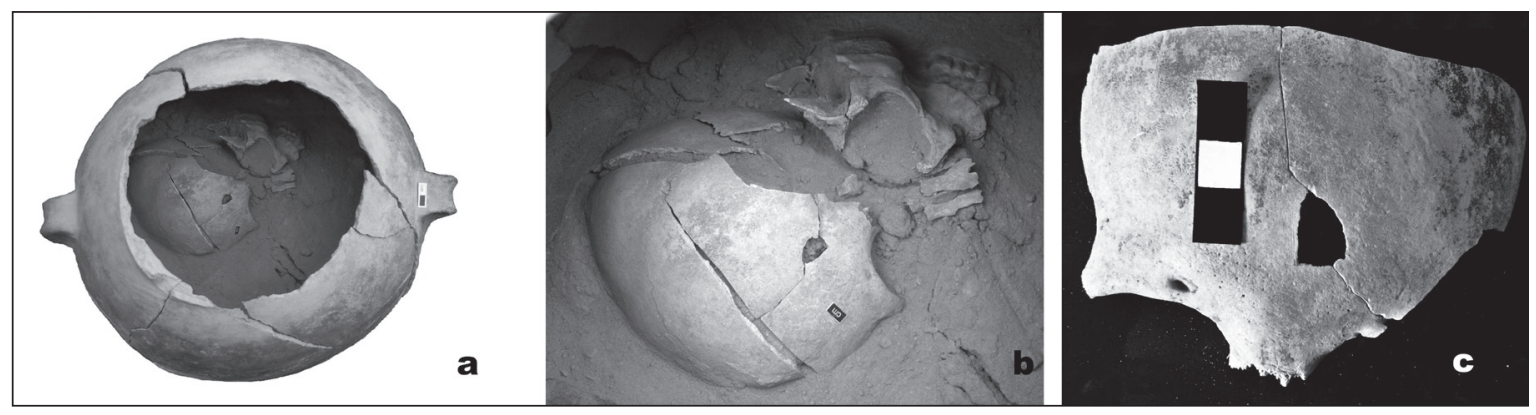

Figura 14. Exhumación de la urna de cerámica (ETU 15). a) La urna de cerámica con el cráneo en su interior; b) Vista del cráneo y orificio en el hueso frontal; $\mathbf{c}$ ) Detalle del orificio en el hueso frontal.

Los análisis bioantropológicos realizados, de acuerdo a las lesiones óseas observadas, han puesto de manifiesto que, tanto las fracturas que se inician en el orificio del frontal izquierdo, como la fractura transversal, representan fracturas post mortem. La falta de restos de la parte basal del cráneo no permite determinar la situación en que se produjo el cercenamiento y separación de la cabeza del cuerpo o decapitación del individuo. En cuanto a la determinación del sexo y edad, la observación del margen supra-orbital, del ángulo gonial y del hueso occipital (parcial), bien definidos y robustos, indican que dicho cráneo correspondería a un individuo masculino de edad adulta (Godoy 2008), y, a partir del estudio del desgaste dental según el método de Brothwell (1963), con una edad aproximada de 25-30 años (Urízar y Castellanos 2009).

\section{* Discusión y COMENTARIOS}

Hasta no hace mucho se ha observado una fuerte tendencia a complejizar las interpretaciones en torno al origen, propósito y significado de las denominadas "cabezas trofeo" Nasca (Forgey y Wlliams 2003), considerando, quizá, que tal complejización ha sido producto de la dificultad existente en demostrar qué existe realmente detrás de las prácticas reconocibles en ellas, tales como "decapitaciones", "conflictos bélicos", "batallas rituales", "cultos a los antepasados" o "ritos de fertilidad agrícola", entre otros (Proulx 1971, 1989, 2001; Coelho 1972; Neira y Coelho 1972-1973; Baraybar 1987; Carmichael 1988; 1994, 1995; Browne et al. 1993; Verano 1995; DeLeonardis 2000; Kellner 2002; Conlee 2007; Conlee et al. 2009), y las situaciones sociales que las produjeron. 
Los hallazgos de un importante número de cabezas cercenadas Nasca (en Carapo, Chaviña, Cahuachi, etc.), pertenecientes, en su gran mayoría, a hombres jóvenes-adultos (Verano 1995; Williams et al. 2001; Tung 2007), predispuso la lectura de "conflictos bélicos" inicialmente propuesta por Uhle (1914), por lo cual las cabezas cercenadas se convertían en trofeos de guerra, o producto de posibles "batallas rituales" (Coelho 1972; Neira y Coelho 19721973) donde las víctimas decapitadas habrían sido jóvenes guerreros prisioneros (Verano 1995). Alentaron esta explicación las evidencias de huellas de lesiones perimortem que presentaron los cráneos analizados (Baraybar 1987; Browne et al. 1993; Verano 1995), sin dejar de lado la presencia de mujeres y niños, quienes habrían sido víctimas indiscriminadas del conflicto (Verano 1995; Forgey y Williams 2003; Forgey y Williams 2005). Del mismo modo, también se propuso una lectura complementaria, sin excluir las anteriores, en torno a la obtención de víctimas por medios bélicos para luego decapitarlos con fines rituales (Baraybar 1987; Proulx 1989; 2001; Verano 1995). Esto llevó no solo a considerar las prácticas de "decapitación" o "cercenamiento" de cabezas sobre individuos, fueran estos vivos o muertos ${ }^{7}$, como meras acciones para la obtención de cabezas, sino también a proponer una lectura del imaginario religioso Nasca, cuyo soporte ideográfico se encuentra vinculado a posibles ritos de "fertilidad agrícola", "regeneración", "renacimiento" y "culto a los ancestros", tal como lo había señalado Tello (1918) en su momento respecto a las propias cabezas cercenadas y retomado posteriormente por otros investigadores (Coelho 1972; Neira y Coelho 19721973; Carmichael 1988, 1995; Browne et al. 1993; Silverman 1993; DeLeonardis 2000; Proulx 2001; Silverman y Proulx 2002; Conlee 2007). Estas interpretaciones tienen su principal sustento en la referencia iconográfica sobre sus diversos soportes materiales. Es la iconografía la que

\footnotetext{
7 La ausencia, hasta el momento, de "cráneos trofeos" (calaveras) en la iconografía Nasca, nos permite sugerir que estas cabezas en general fueron momificadas para mantener los aspectos faciales del rostro (Verano 1995, 2003) (ver Figura 2), tal como se representan en la iconografía (ver Figuras 3, 5 y 11) y a diferencia de como se encuentran en el registro arqueológico, en su mayoría en mal estado de conservación debido a los diversos procesos tafonómicos (p.e., cabeza cercenada de El Trigal). Esto hace suponer que debió existir poco margen de tiempo desde la muerte del individuo hasta la preparación de la "cabeza trofeo", por lo cual se hace menos sustentable la hipótesis de una toma de cabezas de cuerpos muertos de larga data.
}

dará cuenta, en su ejecución, de la materialidad del soporte ideográfico mediante la plasmación de estas cabezas en sus diversas variantes figurativas.

Al respecto, las representaciones de "cabezas trofeo" en la iconografía Nasca, como hemos mencionado, se encuentran asociadas a un alto porcentaje de elementos religiosos (personajes sobrenaturales) (ver Figura 5) y motivos agrícolas, principalmente durante el período Nasca Temprano -incluso desde época Paracas (Frame 2001; Proulx 2001) - y a una asociación progresiva con motivos de carácter bélico (armas y guerreros), en los períodos más tardíos. Esta situación ha llevado a algunos investigadores a inferir un proceso transitorio acerca del uso y significado de estas cabezas en el tiempo y su correlato, de acuerdo al registro arqueológico, con los procesos sociopolíticos de esta sociedad (Roark 1965; Silverman 1993; Silverman y Proulx 2002): del uso ritual-religioso, en un primer momento, con la manipulación de estas cabezas por sacerdotes o chamanes en ritos de "fertilidad", "regeneración" y "ancestros"; al uso político-normativo, en un segundo momento, con la manipulación de las mismas por jefes guerreros para ostentar la afirmación y consolidación de su poder en un determinado territorio (Browne et al. 1993; Silverman 1993), sin excluir, principalmente, el contexto ritual que las envuelve (Proulx 2001; Kellner 2002). Consideramos que este énfasis ritual crea cierta ambigüedad en la interpretación de hechos violentos detectados en el registro arqueológico (Arkush 2012), sobre todo en las evidencias bioantropológicas (Baraybar 1987; Drusini y Baraybar 1991; Browne et al. 1993; Verano 1995; DeLeonardis 2000; Williams et al. 2001; Kellner 2002; Conlee 2007; Tomasto 2009, entre otros), por resaltar una lectura de la realidad simbólica que naturaliza estas prácticas ("batallas rituales"; "ceremonias de sacrificio", "ritos de fertilidad", etc.) frente a la realidad histórica de quienes las ejercieron y padecieron (agresiones, decapitaciones, conflictos, explotación, etc.).

Por otra parte, existe un cierto consenso (Verano 1995; Proulx 2001; Silverman y Proulx 2002) en que las prácticas de culto a los ancestros ${ }^{8}$ (ver discusión en Silverman y Proulx 2002), que sugieren algunos a partir de escenas de

\footnotetext{
8 Prácticas rituales que encuentran su principal apoyo en las fuentes etnográficas y etnohistóricas relacionadas al uso religioso de restos humanos (Silverman y Proulx 2002; Arnold y Hastorf 2008).
} 
enterramiento de cabezas cercenadas en la iconografía (ver Figura 3b) y otros referentes materiales (Carmichael 1988), no tienen relación alguna con estos singulares "objetos". No existe ninguna correspondencia entre el objeto de culto (la "cabeza trofeo") y el sujeto de culto (el "antepasado"). El limitado perfil demográfico de los individuos a quienes cercenaron las cabezas (hombres/jóvenes-adultos) sugiere más bien una consecuencia de posibles conflictos y no producto de la veneración de antepasados (Verano 1995; Proulx 1989, 2001; Williams et al. 2001). Igualmente, el mayor número de representaciones figurativas de "cabezas trofeo" con personajes sobrenaturales y/o personajes guerreros sujetándolas (ver Figura 5), escenas con exposición de cabezas (ver Figura 3a) y las propias escenas de decapitación (ver Figura 4), son elementos inconfundibles en el reconocimiento de mecanismos que exacerban la intimidación y denotan la violencia existente detrás de ellas. Representaciones que, lejos de simbolizar cualquier tipo de culto a los ancestros, tienen su correlato empírico en la caracterización de las mismas "cabezas trofeo", tales como el orificio del hueso frontal donde se introduce la cuerda para sujetarla y/o exponerla (ostentando el poder de los personajes que las sujetan o exponiéndose, colgada como posible ejemplo punitivo) o la momificación facial con alfileres de cactus sellando la boca y los ojos, que se registran en algunos casos (ver Figura 2). Si bien esta última caracterización formaría parte de la preparación de estas cabezas (Verano 1995), podría denotar, además, expresiones simbólicas para acallarlas y cegarlas reprimiendo cualquier intencionalidad de acción participativa entre los vivos. Así, existe una enorme diferencia entre el uso religioso de restos humanos asociado a la veneración de antepasados y el uso de estas "cabezas trofeo" (Proulx 1989, 2001; Silverman y Proulx 2002). Sin embargo, no descartamos la existencia de estas prácticas de veneración, aunque ajenas al uso de estos "objetos", principalmente por la ausencia de las características que los definen como tales, en un contexto de mediación político-ideológica e intimidación.

En los últimos años los trabajos bioarqueológicos (osteológicos y físico-químicos), motivados por el alcance de nuevas tecnologías, han permitido dilucidar mejor el camino para el entendimiento de estos "objetos" que documenta el registro arqueológico en los Andes Centrales (Williams et al. 2001; Kellner 2002, 2006; Forgey y Williams 2003; Forgey y Williams 2005; Tung 2007; Tung et al. 2007; Tung y Knudson 2008; Finucane 2008;
Conlee et al. 2009; Knudson et. al. 2009), colocando sobre el tapete una serie de cuestionamientos sobre el origen y significado de las denominadas "cabezas trofeo".

En este contexto, los análisis físico-químicos, tales como exámenes de isótopos de estroncio, oxígeno y carbón, sumadas a los de ADN antiguo, efectuados sobre cráneos y cuerpos decapitados recuperados en contextos Nasca (Forgey y Williams 2005; Conlee et al. 2009; Knudson et. al. 2009), señalan que el origen geográfico de estos individuos corresponde a la misma zona geológica de los lugares donde fueron enterrados ("locales") (Knudson et al. 2009), por lo cual se hace menos sustentable la existencia de "conflictos bélicos" con grupos "extranjeros"; eso sin tener en cuenta la ambigua definición de lo "extranjero", dado que no se cuenta con un concepto de frontera para determinar territorios políticos prehistóricos. A diferencia de éstos, los últimos hallazgos de cabezas cercenadas reportados fuera del ámbito Nasca, recuperados en los sitios de Nawinpukio (época Huarpa) (Finucane 2008) y Conchopata (época Wari) (Tung 2007; Tung et al. 2007; Tung y Knudson 2008, 2010), ambos sitios en Ayacucho, según el estudio de paleodietas, dan mayor cuenta de una procedencia geográfica diferenciada de las cabezas cercenadas (locales y no-locales). Incluso, algunos de los cráneos analizados de Conchopata presentan traumas cicatrizados (lesiones antemortem) (Tung et al. 2007), lo cual permite inferir una relación directa con prácticas de violencia física, posibles agresiones o situaciones bélicas, sobre poblaciones foráneas. No obstante, queda por demostrar el grado de interacción y las estrategias de ocupación, pacífica o militar, que hubo con las poblaciones Nasca durante el Estado Wari (Kellner 2002, 2006; Conlee et al. 2009), pues al parecer no todas sufrieron las consecuencias de la represión violenta que muestran los cráneos recuperados en Conchopata. Recientes estudios señalan que previo y durante la expansión Wari, estas prácticas (de tomas de cabeza) continuaron en el ámbito Nasca sin interrupciones ni mayores cambios en su preparación (Kellner 2006), excepto algunas particularidades en la ejecución de las mismas (p.e., "half-cut"), planteando una probable variación a nivel interregional o posibles influencias foráneas (Kellner 2006).

Contrastando evidencias bioantropológicas en contextos Nasca, se han observado muestras de lesiones similares a los cráneos Wari (Tung 2007; Tung et al. 2007), aunque 
asociadas a períodos anteriores. Se trata de dos cráneos que presentan traumas cicatrizados (lesiones ante mortem) y un tercero una lesión peri mortem, que pudo producir la muerte del individuo, todos procedentes de cerro Carapo (Palpa) (Browne et al. 1993). Las lesiones observadas en estos cráneos, asociados al período Nasca Medio, señalan las agresiones físicas violentas que sufrieron los individuos previo o durante el acto de la decapitación (Verano 1995), e igualmente en un posible entorno bélico (de guerra, captura de prisioneros, tortura ritual, etc.) (Baraybar 1987). Del mismo modo, otro cráneo procedente de Majoro Chico (Colección Kroeber, Field Museum of Chicago), en este caso de filiación Nasca Temprano, también registra un trauma craneal con similar característica peri mortem, sin precisar la naturaleza de afectación que tuvo en el individuo (Williams et al. 2001). Paralelamente, la detección de traumas poscraneales y craneales, como consecuencia de lesiones por agresión violenta, en una muestra importante de individuos de poblaciones del valle de Nasca (Kellner 2002) y Palpa (Tomasto 2009), junto a anteriores y recientes hallazgos de cuerpos decapitados (DeLeonardis 2000; Conlee 2007), desmembrados y con heridas por armamento (ver Figura 10a, b) (Godoy 2008; Castro-Martínez et al. 2009), asociados a los diversos períodos de ocupación Nasca, se suman al conjunto de evidencias que señalan un claro ejercicio de prácticas de violencia física, conflictos y/o agresiones, que padeció un segmento importante de la población a lo largo de su historia ocupacional en la región.

Volviendo al origen geográfico de las cabezas e individuos decapitados Nasca que fueron identificados como locales (Conlee et al. 2009; Knudson et al. 2009), creemos que esto no desestima una explicación de situaciones de conflictos bélicos, tal como lo certifican las evidencias de traumas y agresiones con arma en cráneos y cuerpos respectivamente (Baraybar 1987; Browne et al. 1993; Verano 1995; Williams et al. 2001; Kellner 2002; Godoy 2008; Tomasto 2009; Castro-Martínez et al. 2009). A nivel territorial, es comprensible entender que la geografía de ocupación Nasca no mantuvo diferencias tan marcadas (zonas áridas y valles costeños) como la geografía del Estado Wari, de mayor extensión y variados pisos ecológicos (desde zonas altoandinas hasta ocupaciones en los valles de la costa), los cuales permiten identificar áreas geológicas bien definidas. Ante esto, es posible que los análisis que sustentan un origen geográfico local se en- cuentran directamente relacionadas con individuos de las poblaciones costeñas que formaron parte de las comunidades locales pre-Nasca, posteriormente sometidas y subordinadas al control político-ideológico Nasca.

Siguiendo estas líneas de explicación, las fases más antiguas documentadas en El Trigal permiten esbozar el panorama acerca del proceso de desarrollo y descomposición del orden social que sufrieron las comunidades locales preNasca, previo a la consolidación del poder político Nasca. Nuestros trabajos efectuados en el asentamiento formativo de El Trigal (sector I o zona de habitación y sector II o zona cima) (ca. 700-600 a 100-150 AC), de tradición alfarera Paracas, permiten sugerir que el trabajo centralizado en edificios singulares de producción (de almacenes y de patios-talleres), la construcción de sistemas defensivos (terrazas defensivas) - con evidencias de depósitos de proyectiles-, la posible circulación intracomunitaria de productos y el acceso a materia prima (p.e., Spondylus, obsidiana, etc.) de procedencia lejana que hemos documentado en nuestras excavaciones, apuntan hacia un fuerte componente comunitario y de probable autogestión político-económica de la comunidad asentada en El Trigal y probablemente para otras comunidades de la región del río Nasca durante este período (Van Gijseghem 2004). Además, no descartamos la posibilidad de que estos asentamientos estuvieron envueltos en un escenario tenso de enfrentamientos interétnicos $\mathrm{y} / \mathrm{o}$ intercomunitarios o guerras de menor escala (enfrentamientos cortos, asaltos, etc.) (Valdez 2009; Valdez et al. 2010). Enfrentamientos que, tal como lo atestiguan las estructuras defensivas de El Trigal, próximas a los edificios de producción y los proyectiles encontrados en ellas, se debieron quizá a las luchas por la accesibilidad a los recursos básicos de la producción o por la protección ante hurtos (Castro-Martínez et al. 2009, 2011). Hipótesis que requerirá una mayor aportación de contrastación empírica en las investigaciones futuras.

Más adelante, con el abandono del asentamiento formativo de El Trigal (150-100 cal. AC), se produce en el lugar una serie de ocupaciones de su entorno inmediato, principalmente en las superficies bajas, terrazas naturales y laderas, del Cerro Puntilla (sector III o zona de necrópolis y sector IV o zona de terrazas). Aspecto que se aprecia, igualmente, a nivel macro, con el incremento de asentamientos en las laderas bajas de los cerros que encajonan el valle de Aja y en toda la cuenca del río Nasca, marcando 
un patrón diferente en relación a los asentamientos tempranos (sobre laderas y crestas de cerros) de la zona.

Los asentamientos tempranos residuales, que fueron incorporando un sincretismo de estilos alfareros Paracas y Nasca, como es el caso de La Puntilla 1 (Van Gijseghem 2004; De La Torre 2005; De La Torre y Van Gijseghem 2005), son totalmente abandonados hacia 50-100 cal. DC (Van Gijseghem 2004), etapa que marca el desarrollo de una nueva configuración territorial del valle de Nasca jerarquizada por el núcleo de Cahuachi, el mayor establecimiento y la principal expresión de la materialización del poder político-ideológico en la cuenca (Llanos 2010). Tal jerarquización y posible dominio político-ideológico se pueden apreciar, de manera indirecta y como secuela colateral, en las escasas evidencias de ajuares que muestran las tumbas halladas en la necrópolis de El Trigal, correspondiente a esta época. Éstas, a diferencia de las registradas en Cahuachi (Orefici y Drusini 2003) y en otros yacimientos de la región (Isla y Reindel 2006; Isla 2009), de mayor ostentación y complejidad, sugieren que la comunidad asentada en esta parte del valle se vio forzada a transferir una parte destacable de su producción a una emergente clase dominante y cuyo centro político-ideológico comprendería nada menos que el complejo monumental de Cahuachi, durante el período Nasca Temprano (Orefici y Drusini 2003; Bachir 2007; Llanos 2009, 2010).

Del mismo modo, en esta etapa temprana Nasca, la detección de agresiones violentas en poblaciones contemporáneas en la zona (Kellner 2002; Tomasto 2009), además de los hallazgos bioantropológicos de la necrópolis de El Trigal, sugieren que los probables enfrentamientos intercomunitarios o guerras de menor escala que acontecieron previos a la emergencia de Cahuachi, continuaron en este período", aunque con menor frecuencia e intensidad debido, quizá, a la subordinación y control de los pueblos ya sometidos. Esto se ve reflejado en el porcentaje menor, con respecto a otros períodos, de evidencias de lesiones por agresión en los registros bioantropológicos (Kellner 2002), en la localización de asentamientos en zonas bajas y en la ausencia generalizada de sistemas defensivos;

\footnotetext{
9 Al respecto, también llama la atención el hallazgo de una "cabeza trofeo" asociada a cúmulos de dardos atados con trenzas de cabello humano y fibras de algodón, en una estructura ceremonial de Cahuachi (Bachir y Llanos 2006).
}

aunque no necesariamente la localización y estructuración de los asentamientos sean indicio de ausencia de conflictos (Arkush y Stanish 2005). Sin embargo, las recurrentes representaciones de "cabezas trofeo" en la iconografía (Roark 1965; Proulx 1971, 1989, 2001; Blasco y Ramos 1974, entre otros), junto a otros reportes arqueológicos (DeLeonardis 2000; Tomasto 2009) e incluidos los hallazgos en la necrópolis de El Trigal, indicarían, además, el establecimiento, en este período, de prácticas rituales (de pertenencia, subordinación e intimidación) que involucraron el uso de estas cabezas, además de actos de decapitación y desmembramiento de cuerpos. La violencia implícita en dichas prácticas sirvió también para consolidar el dominio de la élite emergente en la región. Un dominio que determinó el abandono de los asentamientos formativos de El Trigal (Castro-Martínez et al. 2009, 2011) y la configuración de un nuevo orden social de los territorios políticos en la región.

Recapitulando, ¿qué existe detrás de las prácticas rituales que involucran "cabezas trofeo"? ¿Cuál es la real fundamentación político-ideológica que les dio origen? Con la emergencia de Cahuachi como centro político-ideológico (Bachir 2007; Llanos 2009, 2010), y la desestructuración y abandono de los asentamientos pre-Nasca, entre 150-100 cal. AC y 50-100 cal. DC, se produce una fuerte inflexión histórica en el valle de Nasca. Se observa la formación de una clase dominante ligada directamente a un poder político-religioso reflejado tanto en las complejas construcciones monumentales como en las elaboradas sepulturas con una importante y destacable presencia de ajuares, en el yacimiento de Cahuachi (Orefici y Drusini 2003; Bachir 2007; Llanos 2009, 2010). Estas expresiones materiales demandaron la gestión de una ingente fuerza de trabajo tanto en su establecimiento como en su mantenimiento. Distante de ser solo un centro de culto y/o de peregrinación (Vaughn y Van Gijseghem 2007) y de considerarse "vacío" (Silverman 1993), los últimos estudios en el lugar señalan que en Cahuachi habitó un grupo dirigente que centralizó el poder político, económico e ideológico, regulando el control de la producción en la zona ${ }^{10}$ (Bachir 2007; Llanos 2009, 2010) y que

\footnotetext{
${ }^{10}$ En los últimos años los trabajos efectuados en Cahuachi por el Centro Italiano Studi e Ricerche Archeologiche Precolombiane (CISRAP) a cargo de Orefici, dejan entrever, de acuerdo a las evidencias recuperadas y a diferencia de Silverman (1993), una ocupa-
} 
gestionó la distribución y el acceso a lo producido en beneficio propio. El interés por mantener esas condiciones desiguales, en beneficio de un grupo minoritario de la población (dirigente), propició la (re)creación de manifestaciones ideológicas (religiosas) de naturalización y legitimación del orden establecido mediante las prácticas rituales. Así, las denominadas "cabezas trofeo" formaron parte de esos rituales, que implicaban actos violentos como la decapitación de individuos (DeLeonardis 2000) y el desmembramiento de cuerpos (Godoy 2008; CastroMartínez et al. 2009), dentro del marco de una política de violencia física muy arraigada, tal como se observa en las recurrentes representaciones de la iconografía Nasca.

Estas prácticas rituales continuaron e incluso se acentuaron en los períodos más tardíos, cuando se produjo una re-estructuración en la organización social Nasca con el abandono del centro de Cahuachi (Silverman 1993) y la formación jerárquica de centros políticos-administrativos regionales en la cuenca del río Grande (Isla y Reindel 2006), hasta la ocupación imperial Wari. Los registros bioantropológicos señalan un incremento de "cabezas trofeo" durante estos períodos (Baraybar 1987; Williams et al. 2001; Kellner 2002, 2006; Browne et al. 2003; Tung 2007; Tomasto 2009). A éstos se suma la presencia de cuerpos sin cabeza con signos evidentes de decapitación (Conlee 2007) y otros de dudosa contextualización (DeLeonardis 2000), que, junto a las cabezas, reflejan el correlato empírico de la violencia física representada con más realismo en la iconografía (ver Figura 4) (Roark 1965; Proulx 2001; Silverman y Proulx 2002).

De acuerdo a lo expuesto, consideramos que estas cabezas cercenadas ("cabezas trofeo"), los cuerpos decapitados (DeLeonardis 2000; Conlee 2007) y las posibles prácticas de cercenamiento, desmembramiento y/o separación

ción permanente en el sitio (Orefici y Drussini 2003; Bachir 2007; Llanos 2009, 2010). Por su parte, tanto Bachir (2007) como Llanos (2009, 2010), sin dejar de lado la importancia ceremonial del complejo y de acuerdo a un análisis exhaustivo de la arquitectura monumental y del registro material documentado, destacan la función dirigencial que cumplió el sitio a nivel político y económico durante el denominado período Nasca Temprano (50 AC.-40o DC). Así, ligado a una institucionalización del poder y una regulación de la producción mediante íconos religiosos, se designa a Cahuachi como un "centro ceremonial habitado y lugar de poder" perteneciente a una sociedad compleja de tipo estatal (Bachir 2007). de cabezas y miembros (Godoy 2008; Castro-Martínez et al. 2009), junto al grupo de evidencias de traumas por agresión violenta que brindan los análisis osteológicos (Kellner 2002; Godoy 2008; Castro-Martínez et al. 2009; Tomasto 2009), derivan del ejercicio de políticas de violencia física que padecieron las poblaciones subordinadas y sometidas a un poder político e ideológico centralizado, sujetas tanto para épocas tempranas al centro de Cahuachi (Orefici y Drusini 2003; Bachir 2007; Llanos 2009; 2010), como para épocas tardías a otros centros regionales de la zona (Isla y Reindel 2006). Por tanto, fueron acciones violentas que tuvieron no solo un origen bélico y/o propósito ceremonial, sino también un trasfondo de carácter punitivo e intimidatorio. El propósito, fundamentalmente, fue instaurar el terror a través de la violencia física ejercida, y muchas veces enmascarada por las prácticas rituales, para lograr el dominio y control social de la población. No es extraño que las representaciones simbólicas de estas prácticas y las propias "cabezas trofeo", a través de los diferentes medios y soportes, permitieran instalar una especie de comunicación visual y/o propaganda política que, mediante la religión, naturalizó y legitimó todo acto violento en la vida social de las comunidades explotadas, víctimas del poder institucionalizado.

\section{$*$ Conclusiones}

Los vestigios de la violencia en los Andes Centrales prehispánicos se encuentran sumidos, casi siempre, en la argumentación ideológica de quienes buscan su explicación a partir del registro arqueológico (Arkush 2012). No es de extrañar que los estudios que emprendieron la búsqueda de su naturaleza social a través de los registros funerarios y bioantropológicos, encontraron su principal explicación en el contexto ritual (p.e., Dillehay 1995; Benson y Cook 2001). Al respecto, consideramos que los hechos de violencia física (en los individuos) y simbólica (de las representaciones) en la sociedad Nasca, de acuerdo a situaciones concretas, requieren un reconocimiento y lectura social más allá del esencialismo ideológico (cosmovisión) que pudo plasmarse en el pasado; aquello que racionalizó la violencia física en la vida social de los pueblos mediante prácticas rituales, reduciendo su interpretación a una expresión simbólica de la realidad e invisibilizándola del contexto histórico-social de quienes la padecieron. 
En consecuencia, el ritual se presenta como una comprensión irracional de la realidad cuyo propósito se concreta en la normativización de la conducta social de la población que lo practica. Las denominadas "cabezas trofeo", en el contexto histórico-social que las produjeron y más allá del contexto ritual en que fueron utilizadas, enmascararon una política represiva con la implantación de actos de violencia física-ocultos tras el velo de un discurso ideológico- sobre los pueblos sometidos a un aparato político coercitivo. El componente ideológico (religioso) reguló la naturaleza simbólica de la realidad a través de prácticas rituales y su representación en soportes materiales, desvelando una autoridad política-ideológica de tipo centralizado. De este modo, la iconografía, en sus distintos soportes y expresiones figurativas, contribuyó a cimentar y crear en el imaginario religioso el orden que regulaba las conciencias y creencias de las comunidades, "orden" de obligada adhesión, legitimando y naturalizando toda práctica ritual.

Nuestros recientes hallazgos en la necrópolis de El Trigal indican claras evidencias de actos de violencia sufridos por esta comunidad durante el período Nasca Temprano. A diferencia de otros contextos de restos humanos incompletos procedentes de yacimientos de la época Nasca (Carmichael 1988; Kroeber y Collier 1998, cits. en DeLeonardis 2000: 373-374), que originaron una producción de inferencias no contrastables y una desconfianza del dato empírico, las tumbas selladas e intactas de El Trigal, cuyo contenido presentó cuerpos desmembrados y una "cabeza trofeo", certifican la fiabilidad de los datos y desvirtúan cualquier inferencia de difícil contrastación acerca de los mismos, como por ejemplo, posibles remociones sufridas en épocas prehispánicas (Carmichael 1988, 1995) e incluso en épocas recientes. Si bien no queda clara la naturaleza de los desmembramientos en El Trigal, los exámenes osteológicos preliminares señalan que éstos se produjeron no solo previo al enterramiento, sino también mientras los cuerpos aún conservaban tejido blando (Godoy 2007, 2008). Por tanto, tales acciones dejan un estrecho margen de tiempo desde el acontecimiento que desencadenó la muerte de los individuos. A estas características se suman la lesión por agresión con armamento (punta de flecha) en uno de estos cuerpos sin cabeza, que deja al descubierto, sin lugar a dudas, el ejercicio de la violencia que padeció una parte de la población aquí enterrada. Violencia que se extendió a otras comunidades Nasca, tal como se observa en recientes exámenes osteológicos de una muestra importante de individuos de poblaciones contemporáneas y cercanas a nuestra área de estudio (Kellner 2002; Tomasto 2009). Todo eso, claramente, se encuentra también refrendado por las representaciones iconográficas antes mencionadas.

En la espera de nuevas investigaciones que aporten más datos y contribuyan a clarificar mejor el panorama, las evidencias documentadas hasta el momento en el Trigal y los demás datos analizados en el presente reporte, nos permiten inferir que la producción de "cabezas trofeo" Nasca y el uso de las mismas en prácticas rituales, tiene una directa vinculación con el ejercicio de actos de violencia física ejercidos por una parte de la población. Violencia, principalmente, que estuvo dirigida a intimidar y coaccionar a las comunidades asentadas en el valle de Nasca, durante el período Nasca Temprano, para subordinarlas al poder político-ideológico centralizado de Cahuachi. Estas prácticas violentas continuaron también en períodos más tardíos, aunque en otros contextos de reestructuración política a nivel territorial (Isla y Reindel 2006), hasta la presencia Wari en la región.

\section{* Referencias citadas}

ARANDA, G. y J. A. ESQUIVEL, 2006. Ritual funerario y comensalidad en las sociedades de la Edad del Bronce del sureste peninsular: La Cultura del Argar. Trabajos de Prehistoria 63 (2): 117-133.

ARNOLD, D. y C. HASTORF, 2008. Heads of State: Icons, power, and politics in the ancient and modern Andes. Left Coast Press, Walnut Creek.
ARKUSH, E., 2012. Violence, indigeneity, and archaeological interpretation in the Central Andes. En The ethics of anthropology and Amerindian research, R. Chacón y R. Mendoza (Eds.), pp. 289309. Springer, Nueva York.

ARKUSH, E. y C. STANISH, 2005. Interpreting conflict in the ancient Andes: Implications for the archaeology of warfare. Current Anthropology 46(1): 328. 
BACHIR, A., 2007. Dinámica y desarrollo de un centro ceremonial andino. El caso de Cahuachi. Arqueología y Sociedad 18: 69-94.

BACHIR, A. y O. LLANOS, 2006. El gran templo del centro ceremonial de Cahuachi (Nazca, Perú). Dimensión Antropológica $13(38): 49-86$

BARAYBAR, J., 1987. Cabezas trofeo Nasca: Nuevas evidencias. Gaceta Arqueológica Andina 15: 6-10.

BENSON, E. y A. COOK, 2001. Ritual sacrifice in Ancient Peru. University of Texas Press, Austin.

BLASCO, M. y L. RAMOS, 1974. Cabezas cortadas en la cerámica Nazca según la colección del Museo de América de Madrid. Cuadernos Prehispánicos 2: 29-79.

1980. Cerámica Nasca. Seminario Americanista de la Universidad de Valladolid, Serie Americanista 13, Valladolid.

BLOCH, M., 1989. Ritual, history and power: Selected papers in anthropo$\log$. Athlone, Londres.

BROTHWELL, D., 1963. The macroscopic dental pathology of some earlier human populations. En Dental anthropology, D. Brothwell (Ed.), pp. 271-288. Pergamon Press, Nueva York.

BROWNE, D., H. SILVERMAN y R. GARCÍA, 1993. A cache of 48 Nasca trophy heads from Cerro Carapo, Peru. Latin American Antiquity 4(3): 274-294.

CARMICHAEL, P., 1988. Nasca mortuary customs: Death and ancient society on the south coast of Peru. Ph.D. dissertation, Department of Archaeology, University of Calgary, Calgary.

1994. The life from death continuum in Nasca imagery. Andean Past 4: 81-90.

1995. Nasca burial patterns: Social structure and morturary ideology. En Tombs for the living: Andean mortuary practices, T. Dillehay (Ed.), pp. 161-188. Dumbarton Oaks, Washington D.C.

CASTRO-MARTÍNEZ, P., J. C. DE LA TORRE y T. ESCORIZA, 2008. Proyecto La Puntilla 2007. Prácticas sociales y producción de la vida social en los Horizontes del Formativo-Paracas. Costa Sur de Perú. En Informes y Trabajos del Instituto del Patrimonio Cultural de España, 1: 125:131. Ministerio de Cultura de España, Madrid.

2009. Proyecto La Puntilla (Nasca, Ica, Perú). Avances de las investigaciones 2008. En Informes y Trabajos del Instituto del Patrimonio Cultural de España 3: 181-189. Ministerio de Cultura de España, Madrid.
2011. Proyecto La Puntilla (Nasca, Ica, Perú). Excavaciones en el área del Edificio de los Patios de El Trigal. En Informes y Trabajos del Instituto del Patrimonio Cultural de España 5: 258-267. Ministerio de Cultura de España, Madrid.

COELHO, V., 1972. Enterramentos de cabeças de cultura Nasca. Tesis doctoral. Departamento de Comunicación y Artes, Universidad de Sao Paulo, Sao Paulo.

CONLEE, C. A. 2007. Decapitation and rebirth: A headless burial from Nasca, Peru. Current Anthropology 48(3): 438-445.

CONLEE, C., M. BUZON, A. NORIEGA, A. SIMONETTI y R. CREASER, 2009. Identifying foreigners versus locals in a burial population from Nasca, Peru: An investigation using strontium isotope analysis. Journal of Archaeological Science 36(12): 2755-2764.

CHÁVEZ, S., 1992. The conventionalized rules in Pucara pottery technology and iconography: Implications of socio-political development in the Northern Titicaca Basin. Ph.D. dissertation. Michigan State University, Michigan.

DE LA TORRE, J. C., 2005. Arqueología y sociedad en la costa sur de Perú: Sujetos sociales y espacios domésticos en la sociedad Paracas (1100-100 ANE). Excavaciones arqueológicas en La Puntilla. En América Latina, realidades diversas. Aula Oberta 2001-2005, L Mameli y E. Muntañola (Eds.), pp. 76-90. Institut Catalá de Cooperació Iberoamericana-Centre d'Estudis Internacionals i Interculturals-Universidad Autónoma de Barcelona, Barcelona.

DE LA TORRE, J. C. y P. CASTRO-MARTÍNEZ, 2006. Proyecto Arqueológico La Puntilla (Nasca, Perú) 2005. Sujetos sociales y ámbitos domésticos en la sociedad Paracas. Informe Final 2005. Instituto Nacional de Cultura de Perú, Lima.

2007. Proyecto Arqueológico La Puntilla (Nasca, Perú) 2006. Sujetos sociales y ámbitos domésticos en la sociedad Paracas. Informe Final 2006. Instituto Nacional de Cultura de Perú, Lima.

DE LA TORRE, J. C. y H. VAN GIJSEGHEM, 2005. Excavaciones en La Puntilla (1300-100 ANE): Arqueología en la costa sur de Perú. Revista de Arqueología del Siglo XXI 286: 22-31.

DELEONARDIS, L., 2000. The body context: Interpreting early Nasca decapitated burials. Latin American Antiquity 11(4):363-386.

DILLEHAY, T., 1995. Tombs for the living: Andean mortuary practices. Dumbarton Oaks, Washington D.C.

DRUSINI, A. y J. BARAYBAR, 1991. Anthropological study of Nasca trophy heads. Homo 41: 251-265. 
FINUCANE, B., 2008. Trophy heads from Nawinpukio, Peru: Physical and chemical analysis of Huarpa-era modified human remains. American Journal of Physical Anthropology 135(1): 75-84.

FORGEY, K. y S. WILLIAMS, 2003. Cabezas trofeo Nasca: Evidencias osteológicas y arqueológicas de la colección Kroeber. RevistaAndina 36: 237-261.

2005. Were Nasca trophy heads war trophies or revered ancestors? En Interacting with the dead: Perspectives on mortuary archaeology for the new millenniun, G. Rakita, J. Buikstra, L. Becky S. Williams (Eds.), pp. 251-276. University Press of Florida, Gainesville.

FORKASS, E., 1981. The spotted cat and the horrible bird; Stylistic change in Nasca 1-5 ceramic decoration. Nawpa Pacha 19: 1-62.

FRAME, M., 2001. Blood, fertility, and transformation: Interwoven themes in the Paracas Necropolis embroideries. En Ritual sacrifice in Ancient Peru, E. Benson y A. Cook (Eds.), pp. 55-92. University of Texas Press, Austin.

GODOY, M., 2007. Análisis bioantropológico preliminar de los contextos funerarios de la temporada 2006 en El Trigal (Apéndice 5). En Proyecto Arqueológico La Puntilla (Nasca, Perú).

2006. Sujetos sociales y ámbitos domésticos en la sociedad Paracas, J. C. De La Torre y P. Castro-Martínez. Informe Final 2006. Instituto Nacional de Cultura de Perú, Lima.

2008. Análisis bioantropológico preliminar de los contextos funerarios de la temporada 2007 en El Trigal (Apéndice 6). En Proyecto Arqueológico La Puntilla (Nasca, Perú) 2007. Sujetos sociales y ámbitos domésticos en la sociedad Paracas, P. CastroMartínez, J. C. De La Torre, T. Escoriza, M. Godoy, B. Lapi, I. Navarro, F. Virebayre y J. Zavala. Informe Final 2007. Instituto Nacional de Cultura de Perú, Lima.

HARNER, M., 1972. The Jivaro, people of the sacred waterfalls. Doubleday/Natural History Press, Garden City..

ISLA, J., 2009. From hunters to regional lords: Funerary practices in Palpa, Peru. En New technologies for archaeology: Multidisciplinary investigations in Palpa and Nasca, Peru, M. Reindel y G. Wagner (Eds.), pp. 119-139. Springer, Heidelberg, Berlín, Nueva York.

ISLA, J. y M. REINDEL, 2006. Burial patterns and sociopolitical organization in Nasca 5 society. En Andean archaeology III: North and South, W. Isbell y H. Silverman (Eds.), pp. 374-400. Springer, Nueva York.

KELLNER, C. 2002. Coping with environmental and social challenges in prehistoric Peru: Bioarchaeological analyses of Nasca populations. Ph.D. dissertation. University of California, Santa Barbara.
2006. "Trophy" heads in prehistoric Peru: Wari Imperial influence in Nasca head-taking practices. En Skull collection, modification and decoration, M. Bonogofsky (Ed.), pp. 101-111. BAR International Series 1539, Archaeopress, Oxford.

KNUDSON, K., S. WILLIAMS, R. OSBORN, K. FORGEY y P. WILLIAMS, 2009. The geographic origins of Nasca trophy heads using strontium, oxygen, and carbon isotope data. Journal of Anthropological Archaeology 28(2): 244-257.

KOWTA, M., 1987. An introduction to the archaeology of the Acari Valley in the south coast region of Peru. California Institute for Peruvian Studies, Sacramento.

KROEBER, A., 1956. Toward definition of the Nazca style. American Archaeology and Ethnology 43(4):327-432.

KROEBER, A. y D. COLLIER, 1998. The archaeology and pottery of Nazca, Peru. Alfred L. Kroeber's 1926 Expedition. AltaMira Press, Walnut Creek.

LLANOS, O., 2009. Le bassin du Río Grande de Nazca, Pérou. Archéologie d'un Etat Andin, 200 av. J.-C.-650 ap. J.-C. BAR International Series 1990, Archaeopress, Oxford.

2010. Cahuachi: Residencia y paisaje sacralizado de un centro político Nazca. Revista Española de Antropología Americana 40(1): 27-51.

NÚÑEZ, V, y M. TARTUSI, 2002. Aguada y el proceso de integración regional. Estudios Atacameños 24: 9-19.

NEIRA, M. y V. COELHO, 1972-1973. Enterramientos de cabezas de la cultura Nasca. Revista do Museo Paulista 20: 109-142.

OREFICI, G. y A. DRUSINI, 2003. Nasca. Hipótesis y evidencias de su desarrollo cultural. Centro Italiano Studi e Ricerche Archeologiche Precolombiane (CISRAP), Lima.

PEZZIA, A., 1968. Ica y el Perú precolombino: Arqueología de la provincia de Ica. Ojeda, Ica.

PROULX, D., 1971. Headhunting in Ancient Peru. Archaeology 24(1): 16-21.

1989. Nasca trophy heads: Victims of warfare or ritual sacrifice? En Cultures in conflict: Current archaeological perspectives, D. Tkaczuk y B. Vivian (Eds.), pp. 73-85. Archaeological Association of the University of Calgary.

2001. Ritual uses of trophy heads in ancient Nasca society. En Ritual sacrifice in Ancient Peru, E. Benson y A. Cook (Eds.), pp. 119-136. University of Texas Press, Austin. 
2006. A sourcebook of Nasca ceramic iconography: Reading a culture through its art. University of Iowa Press, Iowa.

ROARK, R., 1965. From monumental to proliferous in Nasca pottery. Nawpa Pacha 3: 1-92.

SILVERMAN, H., 1993. Cahuachi in the Ancient Nasca world. University of Iowa Press, Iowa.

SILVERMAN, H. y D. PROULX, 2002. The Nasca. Blackwell Publishers, Malden.

STRONG, W., 1957. Paracas, Nazca and Tiahuanacoid relationships in South Coastal Peru. Memoirs of the Society for American Archaeology 13 .

TELLO, J., 1918. El uso de las cabezas humanas artificialmente momificadas y su representación en el antiguo arte peruano. Revista Universitaria 2: 477-533.

TOMASTO, E. 2009. Talking bones: Bioarchaeological analysis of individuals from Palpa. En New technologies for archaeology: Multidisciplinary investigations in Palpa and Nasca, Peru, M. Reindel y G. Wagner (Eds.), pp. 141-158. Springer, Heidelberg, Berlín, Nueva York.

TUNG, T., 2007. From corporeality to sanctity: Transforming bodies into trophy heads in the pre-hispanic Andes. En The taking and displaying of human body parts as trophies by Amerindians, R. Chacon y D. Dye (Eds.), pp. 481-504. Springer, Heidelberg, Berlín, Nueva York.

TUNG, T. y K. KNUDSON, 2008. Social identities and geographical origins of Wari trophy heads from Conchopata, Peru. Current Anthropology 49(5): 915-925.

2010. Childhood lost: Abductions, sacrifice and trophy heads of children in the Wari empire of the Ancient Andes. Latin American Antiquity 22(1): 44-66.

TUNG, T., M. CABRERA y J. OCHATOMA, 2007. Cabezas trofeo Wari: Rituales del cuerpo en el recinto ceremonial en " $\mathrm{D}$ " de Conchopata. Revista de Investigación UNSCH 15(2): 216-227.

VALDEZ, L., 2006. Los vecinos de Nasca: Entierros de la tradición Huarato del valle de Acarí, Perú. Bulletin de l'Institut Français d'Études Andines 35 (1): 1-20.
VALDEZ, L. M., 2009. Conflicto y decapitación humana en Amato (valle de Acarí, Perú). Bulletin de l'Institut Français d'Études Andines 38(2): 177-204

VALDEZ, L., J. WILLIAMS, K. BETTCHER y L. DAUSSE, 2010. Decapitación y cabezas humanas del valle de Acarí, Perú.Arqueología y Sociedad 22:39-54.

VAN GIJSEGHEM, H., 2004. Migration, agency, and social change on a prehistoric frontier: The Paracas-Nasca transition in the southern Nasca drainage, Peru. Ph.D. dissertation. University of California, Santa Barbara.

VAUGHN, K. y H. VAN GIJSEGHEM, 2007. A compositional perspective on the origins of the "Nasca cult" at Cahuachi. Journal of Archaeological Science 34: 814-822.

VERANO, J., 1995. Where do they rest? The treatment of human offerings and trophies in ancient Peru. En Tombs for the living: Andean mortuary practices, T. Dillehay (Ed.), pp. 189-227. Dumbarton Oaks, Washington D.C.

2001. The physical evidence of human sacrifice in Ancient Peru. En Ritual sacrifice in Ancient Peru, E. Benson y A. Cook (Eds.), pp. 165-184. University of Texas Press, Austin.

2003. Mummified trophy heads from Peru: Diagnostic features and medicolegal significance. Journal of Forensic Sciences 48(3): 525-530.

2008. Trophy head-taking and human sacrifice in Andean South America. En Handbook of South American Archaeology, H. Silverman y W. Isbell (Eds.), pp. 1045-1058. Springer, Nueva York.

WILLIAMS, S., K. FORGEY y E. KLARICH, 2001. An osteological study of the Nasca trophy heads collected by A. L. Kroeber during the Marshall Field Expeditions to Peru (1925-1926). FieldianaAnthropology Series 33.

UHLE, M., 1914. The Nazca pottery of ancient Peru. Proceedings of the Davenport Academy of Sciences 3: 1-16.

URÍZAR, M. y D. CASTELLANOS, 2009. Análisis bioantropológicos de los contextos funerarios del Proyecto La Puntilla 20062007 (Apéndice 5). En Proyecto Arqueológico La Puntilla (Nasca, Perú) 2009. Sujetos sociales y ámbitos domésticos en la sociedad Paracas, P. Castro-Martínez, J. C. De La Torre y T. Escoriza. Informe Final 2008. Instituto Nacional de Cultura del Perú, Lima. 